\title{
PECULIARITIES OF 630.0 AND 557.7 nm EMISSIONS IN THE MAIN IONOSPHERIC TROUGH: MARCH 17, 2015
}

\author{
N.A. Zolotukhina \\ Institute of Solar-Terrestrial Physics SB RAS, \\ Irkutsk, Russia,zolot@iszf.irk.ru

\section{N.M. Polekh} \\ Institute of Solar-Terrestrial Physics SB RAS, \\ Irkutsk,Russia,polekh@iszf.irk.ru
}

\section{A.V. Mikhalev}

Institute of Solar-Terrestrial Physics SB RAS, Irkutsk, Russia,mikhalev@isz.irk.ru

\author{
A.B. Beletsky \\ Institute of Solar-Terrestrial Physics SB RAS, \\ Irkutsk,Russia,beletsky@iszf.irk.ru
}

S.V. Podlesny

Institute of Solar-Terrestrial Physics SB RAS, Irkutsk, Russia, step8907@mail.ru

\begin{abstract}
Peculiarities of 557.7 and $630.0 \mathrm{~nm}$ emissions observed in the second step of the magnetic storm main phase at the mid-latitude observatory Tory $\left(52^{\circ} \mathrm{N}\right.$, $103^{\circ}$ E) on March 17, 2015 are compared with the changes in ionospheric parameters above this station, detected from ionospheric sounding data and total electron content maps. We have found that the intensity of the 557.7 and $630.0 \mathrm{~nm}$ emissions noticeably increased after the observatory entered into the longitudinal sector of the developed main ionospheric trough (MIT). The most powerful synchronous increases in intensities of the two emissions are associated with amplification of the westward electrojet during strengthening of the magnetospheric convection. We study the dependence
\end{abstract}

of the ratios between the intensities of $630.0 \mathrm{~nm}$ emission recorded in the north, zenith, and south directions on the position of emitting regions relative to the MIT bottom. The SAR arc is shown to appear initially near the bottom of the MIT polar wall and approach the zenith of the station during registration of F3s reflections by an ionosonde, which indicate the presence of a polarization jet near the observation point.

Keywords: second step of the magnetic storm main phase, 557.7 and $630.0 \mathrm{~nm}$ emissions, main ionospheric trough, polarization jet.

\section{INTRODUCTION}

During night hours on March 17, 2015, the complex of optical instruments installed in the ISTP SB RAS Geophysical Observatory ISTP (GPhO, the village of Tory, geographic coordinates $\varphi=52^{\circ} \mathrm{N}, \lambda=103^{\circ} \mathrm{E}$, corrected geomagnetic latitude $\varphi^{\prime}=47.9^{\circ}$ ) detected intense 557.7 and $630.0 \mathrm{~nm}$ atomic oxygen emissions, defined as mid-latitude aurora [Mikhalev et al., 2018; Mikhalev, 2019]. On the basis of space-time dynamics of the intensities, the authors of the above papers have concluded that the synchronous bursts of 557.7 and $630.0 \mathrm{~nm}$ emissions, which lasted for about an hour, observed on that day were type «a» auroras; and the slowly varying $630.0 \mathrm{~nm}$ emission component was represented by diffuse airglow and/or type «d» aurora, as well as by a stable auroral red arc (SAR arc). Note that mid-latitude auroras are the auroras that are observed from regions far below the «typical auroral zone» [Suzuki et al., 2015].

According to the information collected to date, the aurora types identified in [Mikhalev et al., 2018; Mikhalev, 2019] are associated with the electron fluxes of specific energies precipitating into the atmosphere from various magnetospheric regions [Bame et al., 1967; Rassoul et al., 1993; Frey, 2007; Feldstein et al., 2010; Feldstein et al., 2014; Mishin et al., 2018; Mikhalev, 2019]. Type «a» auroras are excited by electrons with energies $\sim 0.1-10 \mathrm{keV}$, which come to the auroral oval from the central plasma sheet after significant acceleration. The criteria used to identify the central plasma sheet are discussed, for example, in [Baumjohann et al., 1989]. Diffuse auroras are caused by electrons with 0.01-1 keV energies coming from the plasma sheet to ionospheric heights without acceleration [Starkov, 2000]. Note that the diffuse auroras are observed in an extended latitudinal region, projected along the magnetic field onto the entire central plasma sheet [ $\mathrm{Ni}$ et al., 2016]. Type «d» auroras and SAR arcs occur when electrons with energies $\sim 0.01-1$ and $\leq 0.01 \mathrm{keV}$ respectively, which precipitate from the plasmapause region, have an effect on the atmosphere [Rassoul et al., 1993]. At ionospheric heights, to the diffuse auroral zone (diffuse precipitation) corresponds the polar wall of the main ionospheric trough (MIT); and to the plasmapause, its equatorial wall [Khalipov et al., 1985; Feldstein et al., 2010; Mendillo et al., 2013; Deminov, 2015].

Figure 1, $a, b$ shows that the optical data analyzed was obtained during the main phase of a two-step magnetic storm (two-step storm main phases [Gonzalez et al., 2002]), namely at its second step (the second decrease in Dst). At the beginning of this step, from 12:00 to 13:00 UT, the cross-polar cap potential drop increased from 50 to more than $150 \mathrm{kV}$ and remained large until the end of March 17 [Hairston et al., 2016]. In the Northern Hemisphere at 15:00-16:00 UT, the sunward convection moved as far as the corrected geomagnetic latitude $\varphi^{\prime} \sim 30-40^{\circ} / 40-50^{\circ}$ in dusk/dawn sectors 

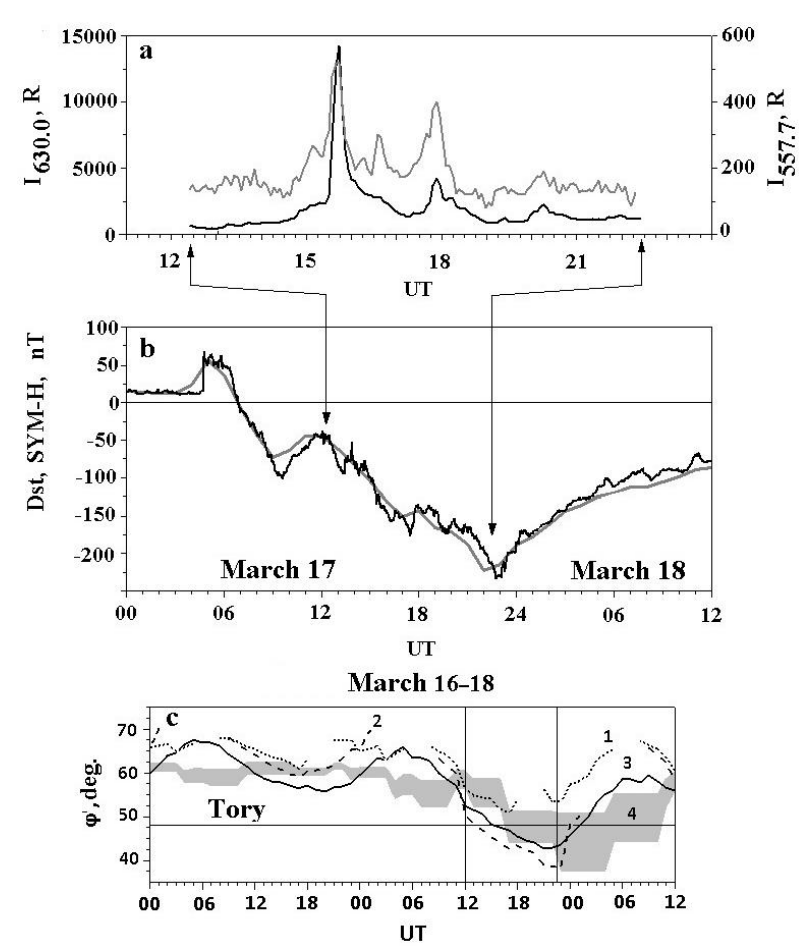

Figure 1. Variations in 630.0 and $557.7 \mathrm{~nm}$ emission intensities (black and gray lines) in a northerly direction, measured by a patrol spectrograph on March 17, 2015 (a); in SYM-H and Dst (black and gray lines) $(b)$; in corrected geomagnetic latitudes $\varphi^{\prime}$ of the equatorial edge of diffuse precipitation zone (1), MIT bottom $(2,3)$, and plasmapause (4), determined for the meridian of $105^{\circ} \mathrm{E}$ by the models developed in [Gussenhoven et al., 1983; Zherebtsov et al., 1986; Deminov, Shubin, 2018; Moldwin et al., 2002] (c). Vertical lines indicate the beginning and the end of optical observations (12:00-22:30 UT, March 17); the horizontal line is the GPhO latitude (Tory)

[Hairston et al., 2016]; the nightside auroral oval expanded to $\varphi^{\prime} \sim 50^{\circ}$ [Le et al., 2016; Kosar et al., 2018]; centers of auroral electrojets shifted to $\varphi^{\prime} \sim 55^{\circ}$ [Jacobsen, Andalsvik, 2016; Zolotukhina et al., 2016; Zolotukhina et al., 2017]. At around the same time, MIT shifted at $\lambda=120^{\circ} \mathrm{E}$ to $\varphi=52^{\circ} \mathrm{N}\left(\varphi^{\prime} \sim 48^{\circ}\right)$ [Polekh et al., 2016], and the $557.7\left(I_{557.7}\right)$ and $630.0 \mathrm{~nm}\left(I_{630.0}\right)$ emission intensities, observed at $\mathrm{GPhO}$ in a northerly direction, sharply increased to maximum values of $\sim 0.5$ and $14 \mathrm{kR}$ respectively for the event considered [Mikhalev et al., 2018; Mikhalev, 2019].

Results of the calculations (Figure 1,c) made by empirical models, based on $K_{\mathrm{p}}$ or $a p$ indices, for the $105^{\circ} \mathrm{E}$ meridian close to GPhO show that on March 17 the latitudes of the diffuse precipitation zone equatorial edge, MIT bottom, and plasmapause might have been by $10^{\circ}-20^{\circ}$ lower than at the same hours on March 16. In this case, at 15:00-18:00 UT (22:00 01:00 LT) the boundary of diffuse precipitation might have been by $3^{\circ}-5^{\circ}$ northward of GPhO; and the plasmapause and the MIT bottom from 15:00 UT (22:00 LT), near it or southward of it.

The MIT shift to midlatitudes is a rare event. Calculations made by the model [Deminov, Shubin, 2018] suggest that at $\lambda=105^{\circ} \mathrm{E}$ the MIT bottom can shift to $\varphi^{\prime}=50^{\circ}$ at dusk only when $K_{\mathrm{p}} \geq 8 \quad(a p \geq 207)$, i.e. during severe and extreme magnetic storms [https://www.swpc. noaa.gov/noaa-scales-explanation].
Even more rare are the cases of occurrence of auroras with intensities higher than $1 \mathrm{kR}$ at midlatitudes because their observation is limited to night hours and weather conditions (clouds). For example, during the past two solar cycles GPhO has detected only seven such cases. All of them occurred during severe and extreme magnetic storms with minimum $D s t<-222 \mathrm{nT}$, including the storm we analyze [Mikhalev, 2019].

Hence it becomes relevant to study the relationship between the dynamics of mid-latitude auroras and magnetospheric-ionospheric disturbances for each individual case. In this paper, we conduct this research for the auroras observed by GPhO on March 17, 2015 at the second step of the geomagnetic storm main phase, i.e. during secondary ring current amplification. Our main purpose is to examine relationships between the dynamics of auroral airglows and that of MIT structural elements. To solve this problem, we will carry out a comparative analysis of the space-time dynamics of intensities of the 557.7 and $630.0 \mathrm{~nm}$ emissions observed at $\mathrm{GPhO}$, changes in ionospheric parameters over this observatory, the total electron content (TEC) along the $105^{\circ} \mathrm{E}$ meridian, and geomagnetic disturbances observed eastward and westward of GPhO.

\section{DATA AND METHODS}

1.1. The optical data in use has been acquired at the complex of instruments described in [Mikhalev et al., 2018]. For quantitative analysis, we have used values of $I_{\mathrm{N}}, I_{\mathrm{Z}}, I_{\mathrm{S}}\left(630.0 \mathrm{~nm}\right.$ emission intensities) and $T_{\mathrm{N}}, T_{\mathrm{Z}}, T_{\mathrm{S}}$ (Doppler temperatures determined for the $630.0 \mathrm{~nm}$ line), measured with the Fabry-Perot interferometer (FPI) in the north, zenith, and south directions respectively [Vasilyev et al., 2017]. In addition, we have analyzed variations in intensities of the 557.7 and $630.0 \mathrm{~nm}$ emissions $\left(I_{557.7}\right.$ and $\left.I_{630.0}\right)$, estimated by the patrol spectrograph for the atmospheric research (SATI-1M) at $63^{\circ}-71^{\circ}$ zenith angles [Mikhalev et al., 2018]. Over the period considered, FPI ( $3^{\circ}$ aspect angle) worked at a wavelength of $630.0 \mathrm{~nm}$ in a mode of patrol survey of five directions cardinal points (elevation angle $\psi=30^{\circ}$, sampling period $\Delta t=254 \mathrm{~s})$, and zenith $\left(\psi=90^{\circ}, \Delta t=127 \mathrm{~s}\right)$. The patrol spectrograph $\left(\psi \sim 23^{\circ}, \sim 8^{\circ}\right.$ inclination to the geographic meridian, $\sim 25^{\circ}$ angular field of view, $\Delta t=260 \mathrm{~s}$ ) was oriented to the north.

Images taken by an all-sky camera KEO Sentinel (viewing direction is zenith, $145^{\circ}$ field of view, $30 \mathrm{~s}$ exposure time; spectrophotometric calibration was performed from starry sky images [Shindin et al., 2017]) were used to analyze the space-time dynamics of the SAR arc; those taken by a wide-angle color camera FILIN-1Ts $\left(\sim 85^{\circ}\right.$ angular field of view, $300 \mathrm{~s}$ exposure time), to study spatio-temporal variations in midlatitude emissions. In the north, the FILIN-1Ts field of view is limited by the Sayan Mountains $\left(\psi \sim 10.5^{\circ}\right)$.

1.2. According to different literature sources, the 557.7 and $630.0 \mathrm{~nm}$ emissions are excited at heights $h=90-240 \mathrm{~km}$ and $h=150-400 \mathrm{~km}$ respectively; and SAR arcs, at $h=400-450 \mathrm{~km}$ [Alekseev et al., 1975; Khomich et al., 2008; Zverev et al., 2012; Mendillo et al., 2013; Feldstein et al., 2014; Tashchilin, Leonovich 2016; Megan Gillies et al., 2017; Aruliah et al., 2019]. 
Following [Mendillo et al., 2013], we assume that 630.0 $\mathrm{nm}$ emission intensity peaks at $h=200 \mathrm{~km}$ (diffuse airglows) and $h=400 \mathrm{~km}$ (SAR arcs); whereas the 557.7 $\mathrm{nm}$ emissions, at $h=100 \mathrm{~km}$.

In the spherically stratified approximation at these heights and at the angles mentioned in Section 1.1, SATI-1M obtained data from latitudes spaced apart from the GPhO latitude by $\Delta \varphi^{\prime} \sim 1.7^{\circ}-2.4^{\circ}(557.7 \mathrm{~nm}$ emission), $\Delta \varphi^{\prime}=3.2^{\circ}-4.5^{\circ}$ (diffuse airglows), and $6^{\circ}-8^{\circ}$ (SAR arc). The FPI data from the north and south directions corresponds to the regions spaced away from GPhO by $\Delta \varphi^{\prime} \sim 2.9^{\circ}$ at $h=200 \mathrm{~km}$ and $5.4^{\circ}$ at $h=400 \mathrm{~km}$. To the zenith direction correspond the GPhO latitude $\left(\varphi^{\prime}=47.9^{\circ}\right)$ and the $103^{\circ} \mathrm{E}$ longitude. The KEO Sentinel camera field of view is limited in the north and south to $\Delta \varphi^{\prime}=5.1^{\circ}$ at $h=200 \mathrm{~km}$ and to $\Delta \varphi=9^{\circ}$ at $h=400 \mathrm{~km}$; and that of the camera FILIN-1Ts, in the north to $\Delta \varphi^{\prime}=4.2^{\circ}$ at $h=100 \mathrm{~km}, \Delta \varphi^{\prime}=6.3^{\circ}$ at $h=200 \mathrm{~km}$, and $\Delta \varphi^{\prime}=10.8^{\circ}$ at $h=400 \mathrm{~km}$.

1.3. The study is based on the values of interplanetary medium parameters and geomagnetic activity indices from [http://cdaweb.gsfc.nasa.gov/istp_public]. From the same website, we took data on variations in the geomagnetic field $H$ component, directed to the geomagnetic pole, from the observatories Tiksi and Dikson, (for THEMIS with a sampling period $\Delta t=60 \mathrm{~s}$ ) and TEC time series with latitudinal, longitudinal, and temporal resolutions of $2.5^{\circ}, 5^{\circ}$, and $15 \mathrm{~min}$ respectively (for GPS-deduced 15-minute Total Electron Content (TEC) global maps). The values of the geomagnetic field $X, Y$, and $Z$ components (directed respectively to the north geographic pole, to the east, and vertically downward), measured at the observatories Yakutsk, Da Lat, and Phu Thuy with $\Delta t=60 \mathrm{~s}$, are from [https://www.intermagnet.org/data-donnee/downloadeng.php]; GOES-13, -15 magnetic data with $\Delta t=60 \mathrm{~s}$, from [ftp.swpc.noaa.gov/pub/warehouse].

The MIT dynamics was examined using TEC distributions, often applied for this purpose [Pryse et al., 2006; Mendillo, 2006; Shinbori et al., 2018], values of F2-layer critical frequencies $\left(f_{0} \mathrm{~F} 2\right)$, and F-region minimum virtual heights $\left(h^{\prime} \mathrm{F}\right)$. These values were obtained with one-minute resolution by the manual processing of ionograms from a chirp ionosonde installed in GPhO [Podlesnyi et al., 2013].

Auroral precipitation energy flux density distributions $(\varepsilon)$ have been constructed using data from [https://www.ngdc.noaa.gov/stp/ovation_prime/data] (calculated from the model [Newell et al., 2009]). To determine the latitude of the equatorial boundary of diffuse precipitation, the criterion $\varepsilon=0.2 \mathrm{erg} /\left(\mathrm{cm}^{2} \cdot \mathrm{s}\right)$ [Ding et al., 2017; Kosar et al., 2018] has been adopted. For convenience, according to the features of intensity variations, we have selected eight UT intervals (13:0014:30 (1), 14:30-15:25 (2), 15:25-16:00 (3), 16:00$17: 10$ (4), 17:10-19:00 (5), 19:00-19:45 (6), 19:4521:10 (7), 21:10-22:00 (8). Boundaries of the intervals are marked in the Figures with vertical dashed lines; their numbers are at the top of the panels.

\section{MIT DYNAMICS AT THE GPhO MERIDIAN}

2.1. During optical observations made at $12: 00$ 22:30 UT on March 17, 2015, GPhO went through the 19:00-05:30 LT sector. Figure 1 shows that noticeable changes in $I_{630.0}$ and $I_{557.7}$ occurred after 13:00 UT. From 13:07 to 13:16 UT, $I_{630.0}$ increased by $\sim 300 \mathrm{R}$, and in the plot of $I_{557.7}$ (UT) appeared oscillations with $30-50 \mathrm{R}$ amplitude $\left(\sim 20-30 \%\right.$ of mean $I_{557.7} \sim 150 \mathrm{R}$ at 13:00-14:00 UT). Figure 2 (panel 2) indicates that at 13:00 UT in the TEC distribution along the $105^{\circ} \mathrm{E}$ meridian equatorward of the auroral precipitation zone (auroral oval), a structure consisting of three elements peculiar to MIT - TEC minimum (bottom), polar and equatorial walls - emerged [Pryse et al., 2006]. Note that MIT differs from other high-latitude troughs in that it is located equatorward of the oval [He et al., 2011]. An hour before, at 12:00 UT (panel 1 in Figure 2), there was no structure similar to MIT at $\lambda=105^{\circ} \mathrm{E}$.

2.2. Changes of the MIT bottom latitude, determined from TEC profiles, and the latitude of the equatorial edge of the diffuse precipitation zone are displayed in Figure 3, $a$. In those cases when minimum TEC was observed at one point (see, e.g., panels 2, 4 in Figure 2), the latitude of the MIT bottom is marked with squares. If the TEC values that differ by no more than $5 \%$ from the minimum one are seen at several adjacent points (see panels 5, 6, 8 in Figure 2), their latitudes are joined by rectangles. The TEC values around the MIT bottom were 10-75\% lower than those at the top of the polar wall. Dark gray squares (rectangles) in Figure 3, $a$ are TEC decreases by 25-75 $\%$ at the bottom; light gray ones, by $10-24 \%$. The MIT depth was maximum at 15:30-15:45 UT.

On the basis of the MIT bottom motions, shown in Figure 3, $a$, and considering that TEC maps have a latitudinal resolution of $2.5^{\circ}$, we believe that at 15:3017:30 UT GPhO was near the MIT bottom and then in a broad zone of low TEC, which might have also been an MIT bottom. An expansion of MIT and a decrease in its depth after midnight, similar to that illustrated in panels 6-8 of Figure 2, are described in [Pryse et al., 2006].

2.3. The fact of shift of an MIT-like structure to the GPhO latitude, which has been inferred from TEC distributions, is confirmed by the ionospheric sounding data shown in Figure 3, $b, c$. We can see that at 12:00 UT (19:00 LT) GPhO was under a positive ionospheric disturbance, which completely disappeared by 14:00 UT. During the decrease in the MIT bottom latitude, inferred from TEC distributions, from $\varphi^{\prime} \sim 53.5^{\circ}$ at the end of interval 1 to $\varphi^{\prime} \sim 48.5-51^{\circ}$ at the beginning of interval $3, \mathrm{GPhO}$ observed the $f_{\mathrm{o}} \mathrm{F} 2$ and $h^{\prime} \mathrm{F}$ variations typical of MIT. From 14:15 to 15:30 UT, the F2-layer critical frequency decreased by $\sim 2 \mathrm{MHz}$, and $h^{\prime} \mathrm{F}$ gradually increased by $\sim 240 \mathrm{~km}$. After 15:30 UT and until the end of the day, $f_{0} \mathrm{~F} 2$ was by $\sim 2 \mathrm{MHz}$ lower and $h$ 'F by 100-200 km higher than background ones. 

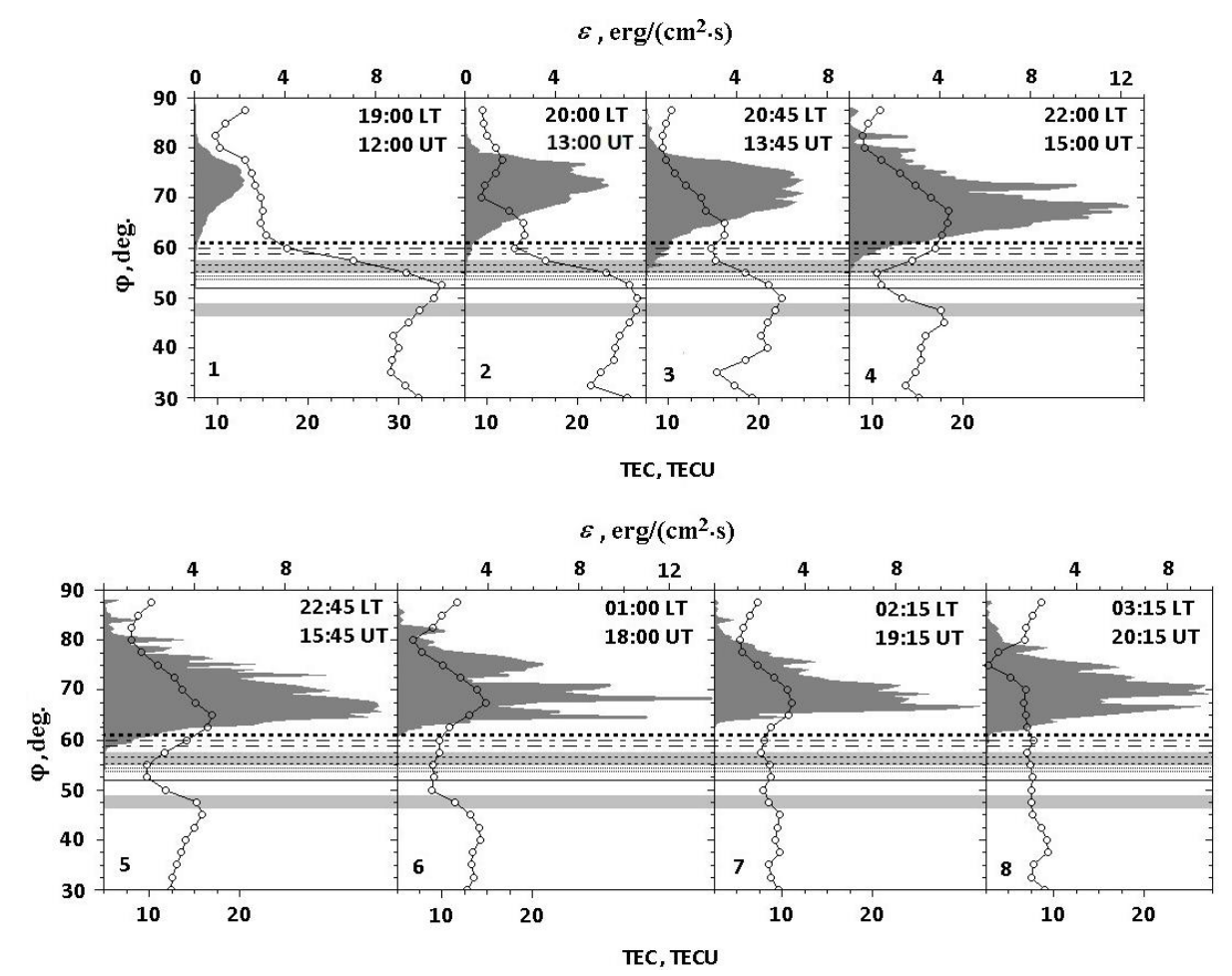

Figure 2. Examples of latitudinal TEC distributions built for March 17, 2015 (lines with open circles) and $\varepsilon$ (solid gray figures) at the $105^{\circ} \mathrm{E}$ meridian. In this and other Figures, gray stripes mark latitudes of the areas covered by the FPI field of view at $h=200-400 \mathrm{~km}$; pairs of dash-dotted and dotted lines, areas falling within the SATI-1M field of view at 400, 200, and $100 \mathrm{~km}$ respectively. Thick solid black and dotted lines indicate latitudes of GPhO and the north horizon of the KEO Sentinel camera at $h=400 \mathrm{~km}$
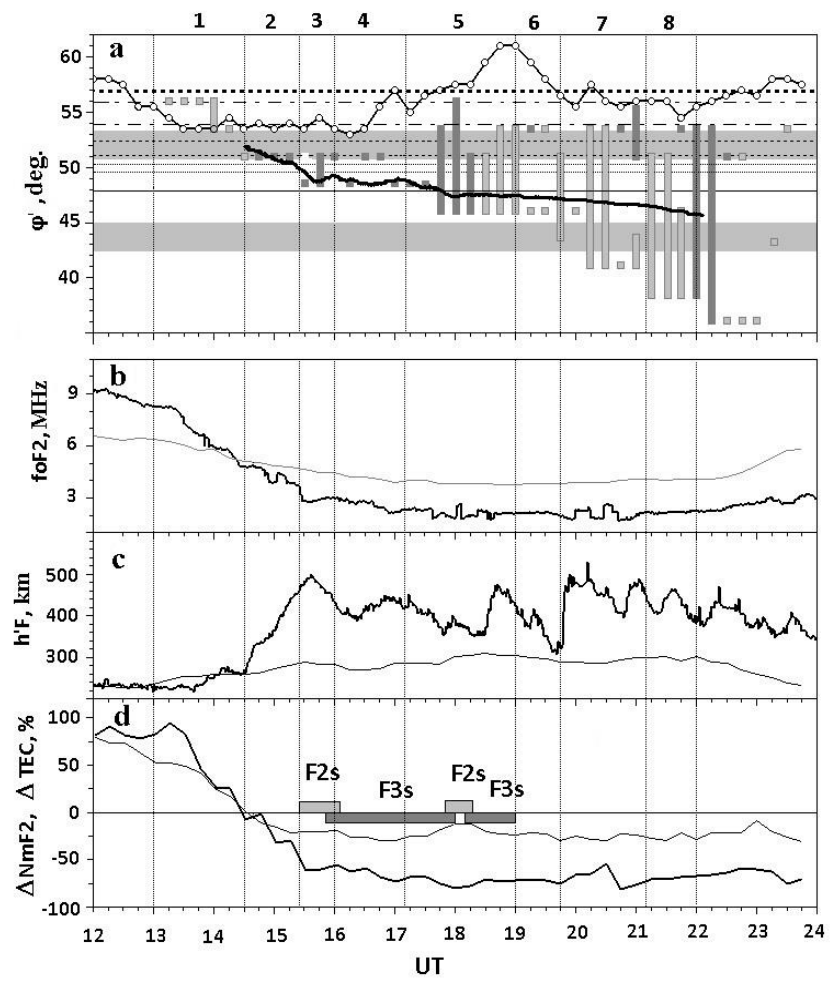

Figure 3. Changes on March 17, 2015 in corrected geomagnetic latitudes of the equatorial edge of the diffuse precipitation zone, calculated by the model [Newell et al., 2009] (line with open circles), the MIT bottom (squares and rectangles), and the SAR-arc center (thick line) (a); current/background (black/gray line) values of $f_{\mathrm{o}} \mathrm{F} 2(a)$ and $h^{\prime} \mathrm{F} 2(b)(b, c)$; normalized deviations of $N_{\mathrm{m}} \mathrm{F} 2$ and TEC (black and gray lines) from background values $(d)$. The background values of $f_{\mathrm{o}} \mathrm{F} 2, h, 2 \mathrm{~F}^{\prime} N_{\mathrm{m}} \mathrm{F} 2$ are equal to their average values obtained on March 13-15. In panel $d$, light gray and dark gray rectangles indicate intervals of detection of F2s and F3s reflections respectively. Vertical lines mark boundaries of the intervals, differing in characteristics of geomagnetic disturbances and airglows observed in them 
Reflections from the regular (background) F2 layer are visible in all ionograms obtained simultaneously with optical measurements. Until 15:18 UT, the ionograms had no significant interference. Reflections from the F2 layer became diffuse after a sharp decrease in $f_{\mathrm{o}} \mathrm{F} 2$ (by $1 \mathrm{MHz}$ for $5 \mathrm{~min}$ ) at the beginning of interval 3 , which occurred against maximum $h^{\prime} \mathrm{F}$. In addition there are oblique reflections with higher frequencies, as compared to reflections from the regular F2 layer, and approximately the same delays in ionograms obtained at 15:25-16:05 and 17:50-18:17 UT. These reflections are similar to the F2s reflections presented in [Filippov et al., 1984; Stepanov et al., 2017]. At 15:52-18:00 and 18:08-19:00 UT, the iongrams exhibit F3s reflections - additional tracks lying within lower frequencies and longer delays than those from the F2 layer [Filippov et al., 1984; Stepanov et al., 2017]. In Figure 3, $d$, the intervals of observation of the F2s and F3s reflections are marked with light gray and dark gray rectangles. Occurrence of F2s reflections in intervals 3 and 5 implies that the MIT polar wall is near a point of observation; and F3s reflections in intervals 4 and 5 indicate a narrow ionization trough in the polarization jet region [Filippov et al., 1984; Stepanov et al., 2017].

Figure 3,d compares plots of normalized deviations of the F2-layer maximum electron density and TEC $\left(\triangle N_{\mathrm{m}} \mathrm{F} 2\right.$ and $\left.\triangle \mathrm{TEC}\right)$ from their background values: $\Delta N_{\mathrm{m}} \mathrm{F} 2$ are determined from $f_{\mathrm{o}} \mathrm{F} 2\left(N_{\mathrm{m}} \mathrm{F} 2=1.24 \cdot 10^{4} \cdot f_{\mathrm{o}} \mathrm{F} 2^{2}\right.$ $\left.\mathrm{cm}^{-3}\right) ; \triangle \mathrm{TEC}$, from TEC values at the point with coordinates $\varphi=52.5^{\circ}, \lambda=105^{\circ}$. The trends in $\Delta N_{\mathrm{m}} \mathrm{F} 2$ and $\Delta \mathrm{TEC}$ are similar, but after 15:30 UT the depth of decrease in $N_{\mathrm{m}} \mathrm{F} 2(\sim 60-75 \%)$ is 3-4 times greater than that in TEC $(\sim 15-25 \%)$. This means that the trough in the F2-layer maximum electron density might have been deeper than that in TEC. The manifestations of ionospheric disturbances identified indicate that after 15:25 UT GPhO entered the MIT zone and possibly remained in it until the end of the day.

\section{GEOMAGNETIC DISTURBANCES IN THE SECTOR OF OPTICAL OBSERVATIONS}

3.1. Figure 4 compares $I_{557.7}$ and $I_{630.0}$ variations with variations in the horizontal magnetic field component at high latitudes. In the time interval considered at the observatories Tiksi $\left(\varphi=71.6^{\circ} \mathrm{N}, \lambda=128.8^{\circ} \mathrm{E}\right.$, $\left.\varphi^{\prime}=66.5^{\circ}\right)$ and Yakutsk $\left(\varphi=62^{\circ} \mathrm{N}, \lambda=127.9^{\circ} \mathrm{E}\right.$, $\varphi^{\prime}=56.8^{\circ}$ ), located by $\sim 25^{\circ}$ eastward of $\mathrm{GPhO}$, and at the observatory Dikson $\left(\varphi=73.5^{\circ} \mathrm{N}, \lambda=80.7^{\circ} \mathrm{E}, \varphi^{\prime}=69.4^{\circ}\right)$, located by $\sim 22^{\circ}$ westward of it, there were multiple negative disturbances in the $X$ (Yakutsk) or $H$ (Tiksi, Dikson) component of the geomagnetic field. Therefore, $\mathrm{GPhO}$ was all this time in the sector of the westward electrojet.

3.2. The $\Delta H_{\text {DLT-PHU }}$ variations (Figure $4, a$ ), i.e. differences between the horizontal geomagnetic field components $\left(H=\left(X^{2}+Y^{2}\right)^{1 / 2}\right)$ measured at the observatories Da Lat $\left(\varphi=11.9^{\circ} \mathrm{N}, \lambda=108.5^{\circ} \mathrm{E}, 2.19^{\circ}\right.$ inclination $)$ and Phu Thuy $\left(\varphi=21^{\circ} \mathrm{N}, \lambda=106^{\circ} \mathrm{E}, 11.2^{\circ}\right.$ inclination $)$, provide information about the direction of electric field near the meridian of magnetic, and in our case also optical, measurements [Blanc, Richmond, 1980; Balan et al., 2010; Polekh et al., 2017]. The gray stripe shows limits of the $\Delta H_{\text {DLT-PHU }}$ variation during magnetically quiet days on March 13-15; the black line indicates current values on March 17. Significant, 10 nT deep, decreases in current values of $\Delta H_{\text {DLT-PHU }}$ relative to the gray stripe in intervals 3,5 , and 7 suggest that the enhanced magnetospheric convection field, directed to the west at night, in them was greater than the eastward field of disturbed dynamo.

3.3. Strong amplifications in the western electrojet, which appeared as deep bay-like depressions in $H$ or $X$ component of the geomagnetic field, were sequentially fixed in intervals 1, 3, 5, and 7. During a substorm with multiple onsets [McPherron, 1978; Nagai et al., 1983], developed in interval 1, the greatest amplification in the field of the westward electrojet with $\Delta H \sim-2000 \mathrm{nT}$ was detected at the auroral observatory Dikson at $~ 13: 40$ UT, after the transition from positive to weak negative disturbance of the geomagnetic field $Z$ component (points to the shift of the westward electrojet center from south to north with respect to the observatory). In interval 2, the $H$ component in Tiksi and Dikson gradually returned to its pre-substorm level, and the $X$ component in Yakutsk non-monotonically decreased. It reached a minimum $(\Delta X \sim-1700 \mathrm{nT})$ at $\sim 15: 40 \mathrm{UT}$ in interval 3 , in which, as the bay-like decrease in $\Delta H_{\text {DLT-PHU }}$ implies, the magnetospheric convection field strengthened, whereas the westward electrojet center shifted to the lowest latitudes and was near Yakutsk [Zolotukhina et al., 2016]. In the same interval there were the highest (among the three pairs of peaks observed by SATI-1M) synchronous peaks of $I_{630.0}$ and $I_{577.7}$.

The $\Delta H_{\text {DLT-PHU }}$ decreases in intervals 5 and 7 also coincide in time with the synchronous peaks of $I_{630.0}$ and $I_{577.7}$, which are smaller than in interval 3, and with the bay-like geomagnetic field depressions, which are the deepest $(\Delta H \sim-1700$ and $-1200 \mathrm{nT})$ at the Observatory Dikson. In contrast, the first, the most intense according to data from the Observatory Dikson, substorm, observed in interval 1, was not accompanied by noticeable changes in the equatorial electric field and by synchronous increases in $I_{630.0}$ and $I_{577.7}$.

\section{RELATIONSHIP BETWEEN OPTICAL, GEOMAGNETIC, AND IONOSPHERIC DISTURBANCES}

4.1. Images taken with the FILIN-1Ts and KEO Sentinel cameras show that near their northern horizons in intervals 1, 5, 7 there were bright discrete structures moving from west to east. The direction of motion of the structures suggests that their primary sources related to substorms were located westward of GPhO (Section 3.3). In interval 3 were bright red vertical flashes of aurora borealis. Relying on the estimated distances to northern horizons of SATI-1M, FILIN-1Ts (Section 1.2) and the variations in the latitude of the equatorial 


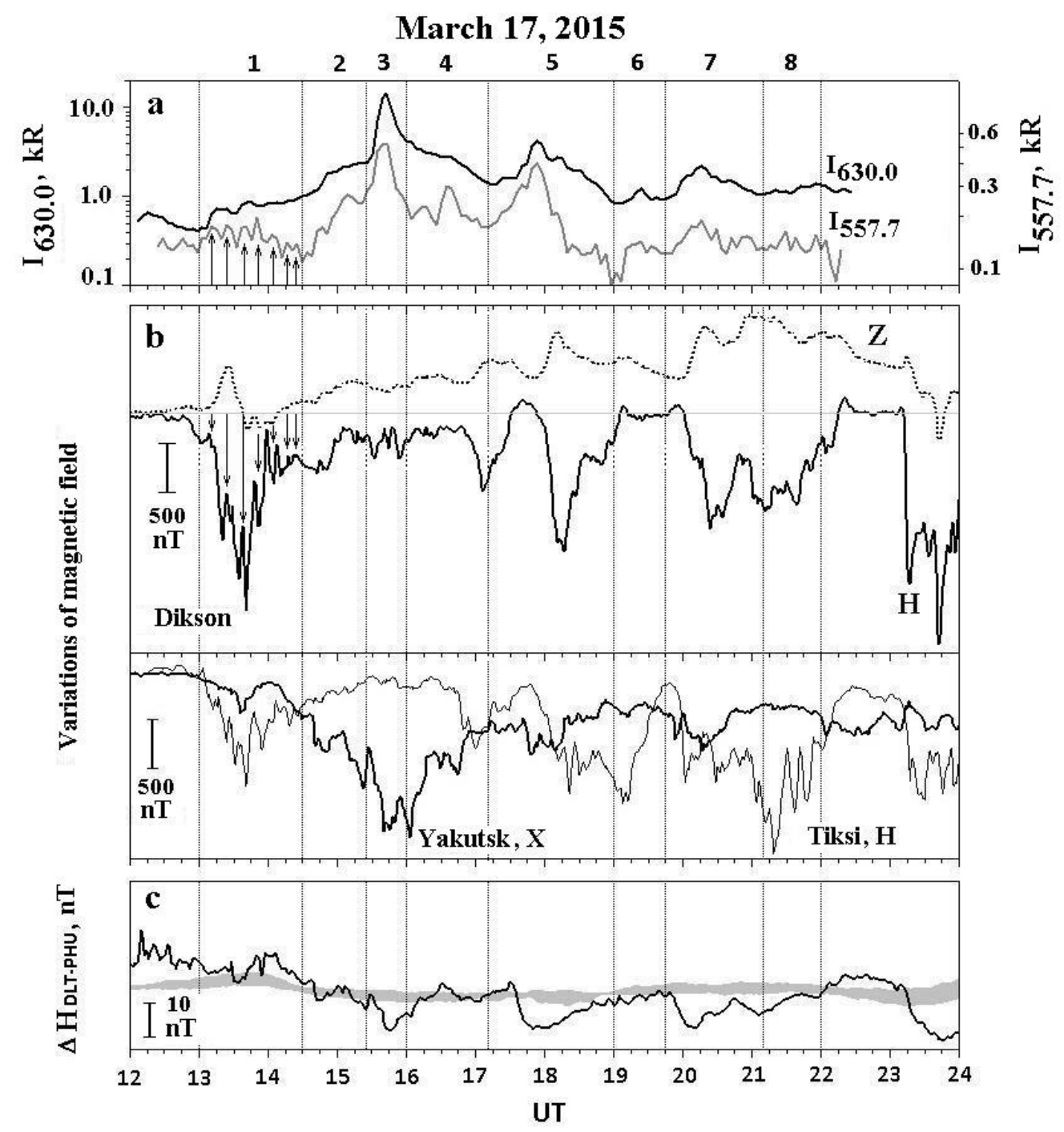

Figure 4. Variations in: the intensity of 630.0 and $557.7 \mathrm{~nm}$ emissions (black/gray line) as derived from SATI-1M data (a); the $H, X$, and $Z$ components of the magnetic field at the three high-latitude observatories $(b) ; \Delta H_{\text {DLT-PHU }}(c)$. In interval 1 , vertical arrows denote the relationship between seven quasi-periodic fluctuations of the westward electrojet field and $I_{577.7}$, which have roughly the same duration and time of occurrence.

edge of the diffuse precipitation zone (Figure 3,a), we believe that auroral precipitation increases during substorms are responsible for the above discrete structures.

4.2. In Section 3.3, we have noted that distinct synchronous peaks of $I_{557.7}$ and $I_{630.0}$ were seen in intervals 3, 5,7 during bay-like decreases in the $H$ or $X$ components of the geomagnetic field, which coincided in time with enhancements of the magnetospheric convection field. In intervals $3,5,7$, the bursts of $I_{557.7}$ and $I_{630.0}$ were preceded by decreases in the latitude of the equatorial edge of the diffuse precipitation zone, characteristic of the substorm growth phase and onset, which were followed by its increases during the transition from the expansion phase to the recovery phase.

4.3. Comparing the plots in Figure 4, $a, b$ shows that a clear connection between geomagnetic disturbances and increases in atomic oxygen emissions was also seen in interval 1 . The $I_{630.0}$ increase by $\sim 300 \mathrm{R}$ at $13: 07-$ 13:16 UT and activation of $\sim 12$ min quasi-periodic $I_{557.7}$ fluctuations (Section 2.1) coincide within the time reso- lution of SATI-1M data with the substorm onset at $\sim 13: 05$ UT and with the appearance of red spots in the FILIN-1Ts images. Arrows in panels $a, b$ of Figure 4 indicate that in interval 1 to each of the $\sim 11-12 \mathrm{~min}$ $I_{557.7}$ oscillations corresponds one of the multiple amplifications of the westward electrojet with the same period. A clear connection between the $I_{557.7}$ peaks and the $X$-component decreases in Yakutsk is also visible in intervals 2 and 3.

Figure 5 shows that jumps in the solar wind dynamic pressure $P_{\mathrm{sw}}$ match geomagnetic field $H$-component fluctuations, recorded at the Observatory Dikson, and $A L$-index variations. We believe that a cause of the multiple amplifications of the westward electrojet (including that beginning in Dikson at $\sim 13: 05$ UT), the rapid increases in $I_{630.0}$, the activation of $I_{557.7}$ fluctuations, and the appearance of red spots might have been solar wind pressure jumps [Meurant et al., 2004; Keika et al., 2009; Tsurutani et al., 2011].

The magnetospheric compressions in interval 1 are confirmed by GOES-13 satellite data $\left(\lambda=285^{\circ} \mathrm{E}\right)$ : three 


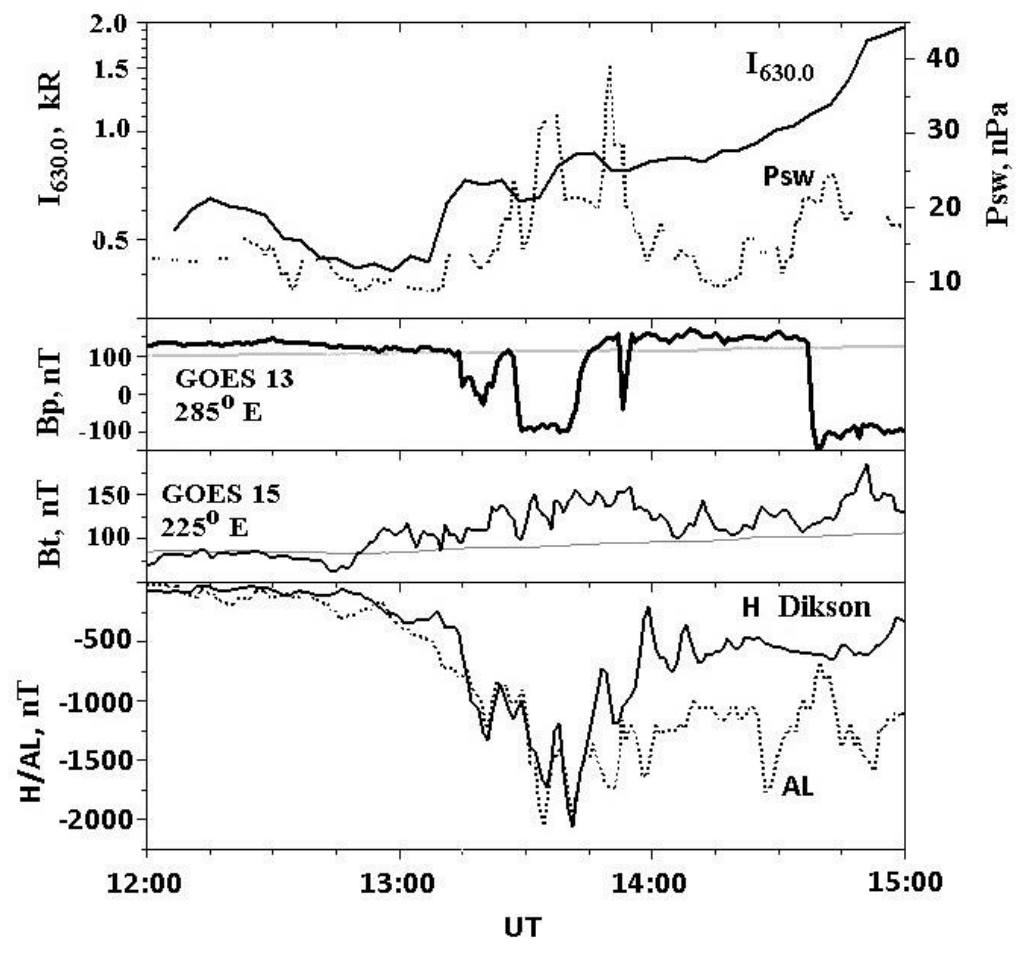

Figure 5. Variations (top to bottom) in: $I_{630.0}$ and $P_{\mathrm{SW}}-$ solar wind dynamic pressure, the $B_{\mathrm{p}}$ component, parallel to the Earth axis, and the $B_{\mathrm{t}}$ magnetic field modulus, measured by the GOES-13 and -15 satellites respectively, the $H$ component of the geomagnetic field at the Observatory Dikson, and the $A L$ index

decreases in the magnetic field $B_{\mathrm{p}}$ component (to -50 , 100 , and again to -50 нТл) recorded by the satellite at 13:00-14:00 UT (08:00-09:00 LT) suggest that the magnetopause shifted to the satellite's orbit. Magnetospheric compressions generate fast magnetosonic waves propagating isotropically at a velocity of $\sim 1000 \mathrm{~km} / \mathrm{s}$, related Alfvén waves, and modulation of magnetosphericionospheric currents and precipitating electron fluxes able to penetrate up to $h=100-400 \mathrm{~km}$ and to increase the 557.7 and $630.0 \mathrm{~nm}$ emissions [Meurant et al., 2004]. Figure 5 shows that at 13:00-14:00 UT GOES-15 observed compression waves (quasi-periodic fluctuations in the geomagnetic field modulus $B_{\mathrm{t}}$ ) in the sector 04:00-05:00 LT. In the case of interest, the electron population in the shells $L \sim 2.5-3.2\left(\varphi^{\prime} \sim 51-56^{\circ}\right)$, adjacent to an area falling within the SATI-1M field of view at $h=200-400 \mathrm{~km}$, might have increased at the storm first step ( 07:00-10:00 UT).

4.4. Throughout the event of interest, the $630.0 \mathrm{~nm}$ emission intensity variations detected by SATI-1M and in a northerly direction by FPI were similar (Figure 6, a). The $I_{630.0}$ peaks mentioned in Section 4.2 are close in time to $I_{\mathrm{N}}$ peaks, as well as to increases in $I_{\mathrm{Z}}$ and $I_{\mathrm{S}}$ (Figure $6, b$ ). Almost simultaneous increases in $I_{\mathrm{N}}, I_{\mathrm{Z}}$, and $I_{\mathrm{S}}$ were also recorded at the beginning of interval 1 and during the substorm onset. This confirms the relationship between activations of the westward electrojet during magnetic storms and increases in atmospheric emissions completely covering the field of view of the all-sky camera placed in midlatitudes [Shiokawa et al., 2005].

Nevertheless, the $I_{\mathrm{N}}$ variations and their related $T_{\mathrm{N}}$ variations in intervals 1,2 are markedly different from those recorded in the zenith and south directions. During the simultaneous increases in $I_{\mathrm{N}}, I_{\mathrm{Z}}, I_{\mathrm{S}}$, which started at $\sim 13: 00, T_{\mathrm{N}}$ increased by $\sim 100 \mathrm{~K}$, whereas $T_{\mathrm{Z}}$ and $T_{\mathrm{S}}$ remained almost unchanged. To the nonmonotonic increases in $I_{\mathrm{N}}$ at 13:30-15:00 UT corresponded increases in $T_{\mathrm{N}}$ while $I_{Z}, I_{\mathrm{S}}$ gradually decreased to minimum for the event under study.

The analysis of latitudinal TEC distributions indicates that in early interval 1 an increase in $I_{\mathrm{N}}, T_{\mathrm{N}}$, and $I_{630.0}$ occurred at latitudes of the northern edge of the positive ionospheric disturbance zone, which coincide with latitudes of the MIT equatorial wall; whereas $I_{\mathrm{Z}}, T_{\mathrm{Z}}$ $I_{\mathrm{S}}, T_{\mathrm{S}}$ variations, inside this zone. At 13:30-14:45 UT, intensity and temperature variations were observed during the transition from positive to negative ionospheric disturbance, i.e. when the ionospheric structure changed in the region studied. By 14:00 UT, $\Delta N_{\mathrm{m}} \mathrm{F} 2$ and $\Delta \mathrm{TEC}$ approached zero, and the eastern edge of the region $\triangle \mathrm{TEC}>0$, which at $12: 00 \mathrm{UT}$ at $\varphi=52.5^{\circ}$ occupied the sector $12-23 \mathrm{LT}$, shifted to $\sim 17: 00 \mathrm{LT}\left(\lambda \sim 45^{\circ}\right.$, Figure 7 , $b)$. The MIT bottom at $\lambda=105^{\circ}$ expanded to $\varphi=57.5^{\circ}$ (Figure 7, $a$, left). By 14:45 UT, the base of the equatorial MIT wall approached the FPI field of view in the north direction, and in the zenith direction this wall fell within the FPI field of view (Figure 7, $a$, center). These changes in the MIT structure do not allow us to determine the position of its structural elements relative to FPI fields of view.

4.5. In intervals 1,2 there are also clear differences between values and variations of $T_{\mathrm{N}}$ and those of $T_{\mathrm{Z}}, T_{\mathrm{S}}$. Figure 6, $b$ shows that at 13:00 UT the Doppler temperature in the north direction only by $\sim 20 \mathrm{~K}$ differed from that observed in the south and zenith directions. In interval 1 

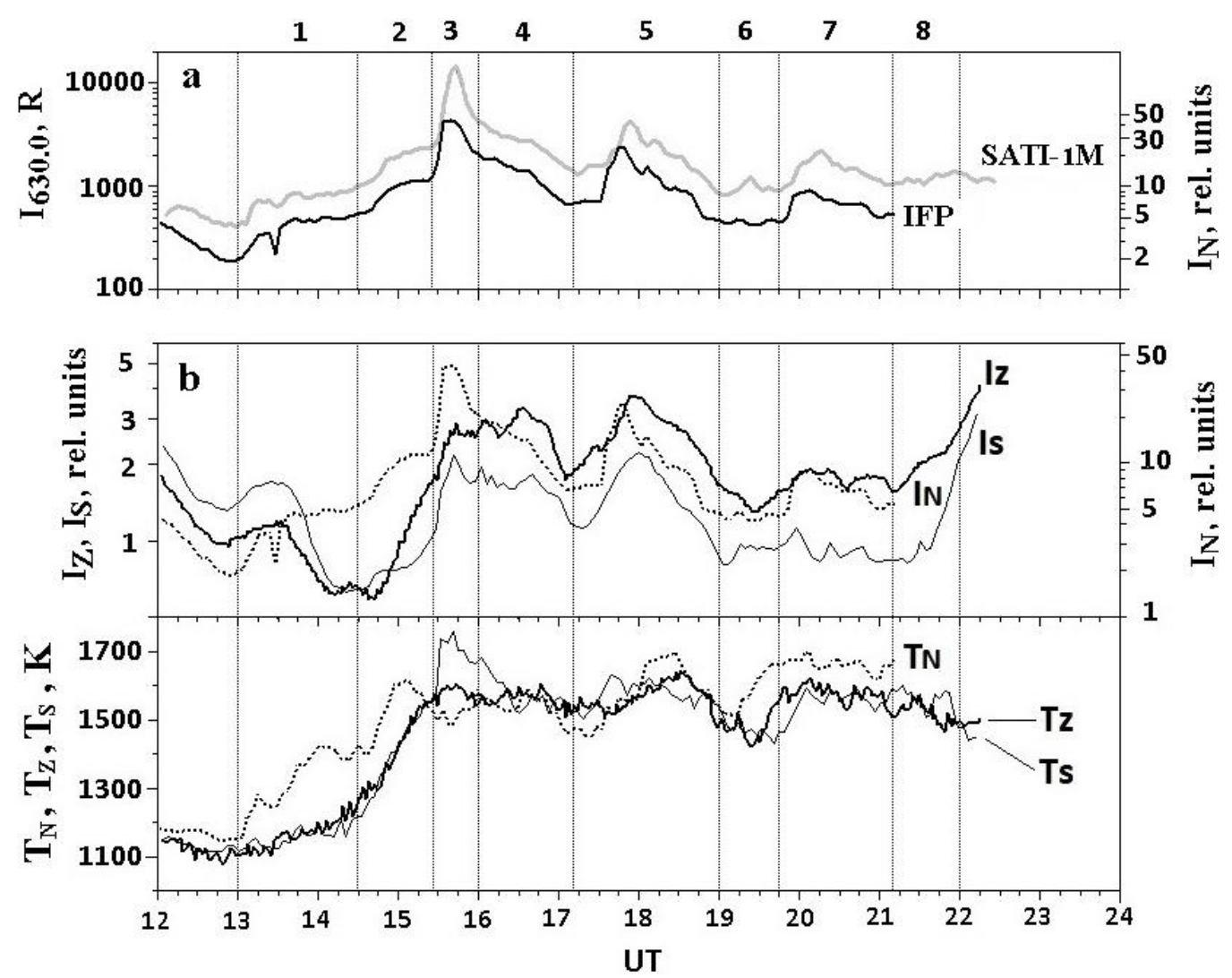

Figure 6. Variations in $I_{630.0}$ and $I_{\mathrm{N}}(a)$, intensities and Doppler temperatures in the north, zenith, and south directions $(b)$
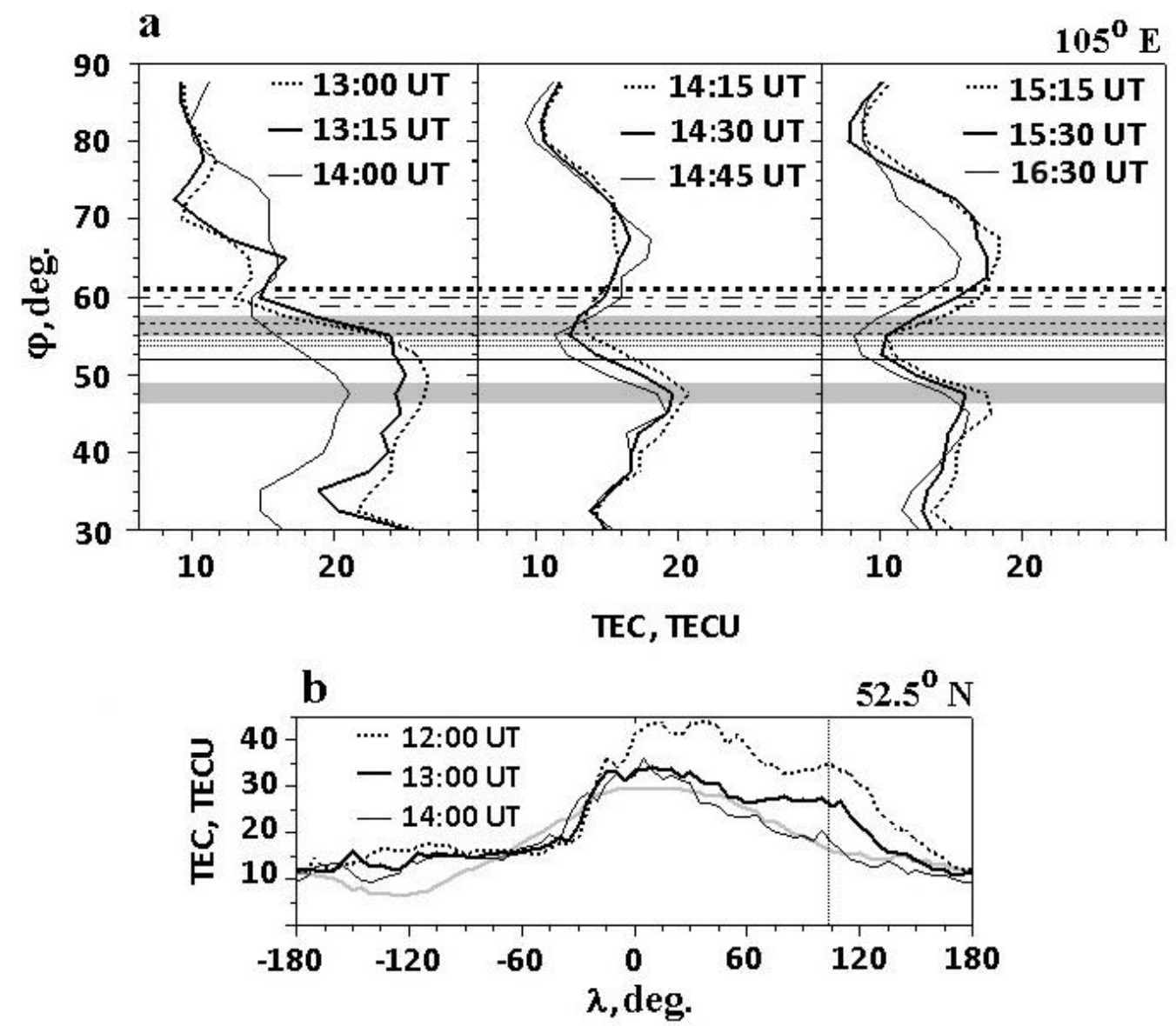

Figure 7. Latitudinal profiles of TEC at the $105^{\circ} \mathrm{E}$ meridian $(a)$ and longitudinal profiles of TEC at a latitude of $52.5^{\circ} \mathrm{N}(b)$ at given moments of time. In panel $b$, the gray line represents background TEC. The vertical dotted line marks the longitude of $\mathrm{GPhO}$ 
and in the first half of interval 2, smoothly growing $T_{\mathrm{Z}}$ and $T_{\mathrm{S}}$ were by $50-250 \mathrm{~K}$ lower than non-monotonically increasing $T_{\mathrm{N}}$, and became equal to it at the end of interval 2 after the northward Doppler temperature began to decrease. The onset of decrease in $T_{\mathrm{N}}$ at 15:05-15:09 UT coincides (within the temporal resolution of FPI data) with the onset of a two-step decrease in $X$ by 600 nT in Yakutsk at 15:05-15:06 UT or with a northward shift of the MIT polar wall to the latitudes of the FPI field of view.

In interval 3, the Doppler temperature in the areas explored with FPI was maximum in a southerly direction and minimum in a northerly direction. At peak intensities recorded by FPI at 15:35-15:45 UT in all directions, $T_{\mathrm{N}}$ was lower than $T_{\mathrm{Z}}$ and $T_{\mathrm{S}}$ by $\sim 100$ and $\sim 250 \mathrm{~K}$ respectively. That time, the FPI fields of view in the north and south directions were on either side of the MIT bottom (on its polar and equatorial walls respectively). Thus, in interval 3 the substorm activity enhancement caused $I_{630.0}$ to increase across the MIT zone, and the Doppler temperature to rise (as at the beginning of interval 1) only in the emitting region located near the latitude of the top of its equatorial wall.

After reaching peak values and until the middle of interval $4, I_{\mathrm{Z}}$ and $I_{\mathrm{S}}$ remained high, whereas $I_{\mathrm{N}}$ decreased threefold. The analysis of latitudinal profiles of TEC, constructed for 16:00-16:30 UT, has shown that the MIT polar wall, its base, and the top of the equatorial wall still persisted in this time period in the FPI field of view in the north, zenith, and south directions respectively. For the next hours, high (low) Doppler temperatures were generally observed concurrently with high (low) intensities. An exception is the rise in $T_{\mathrm{N}}$ by 150 $\mathrm{K}$, which began at 19:14 UT -19 min before a sharp increase in $I_{\mathrm{N}}$

4.6. Figure 8 indicates that the Doppler temperature variations at the zenith of $\mathrm{GPhO}$ are similar to variations in the minimum virtual height of the ionospheric Fregion over this station. After 16:00 UT, the closest similarity between the $T_{\mathrm{N}}$ and $h$ ' F variations is observed if the $T_{\mathrm{N}}$ plot is shifted by $\sim 10 \mathrm{~min}$ along the time axis. Thus, a rise in the F-region virtual height follows an increase in the Doppler temperature of oxygen atoms, determined from the broadening of the $630.0 \mathrm{~nm}$ line. This suggests that the key factor contributing to the strengthening of this emission after 16:00 UT is the increased temperature in the region of the modified atmosphere composition and/or in the polarization jet band [Bryunelli, Namgaladze, 1988; Khalipov et al., 2018]. It is also deemed that during geomagnetic disturbances due to increasing energy exchange between the plasmasphere and the ring current, at midlatitudes the electron temperature rises at F-region heights [Khomich et al., 2008]. The mechanism for strengthening the $630.0 \mathrm{~nm}$ emission in the case of high temperature might be oxygen atom collisions with thermal electrons in the reaction $\mathrm{O}\left({ }^{3} \mathrm{P}\right)+\mathrm{e} \rightarrow \mathrm{O}\left({ }^{1} \mathrm{D}\right)+\mathrm{e}$ in addition to the dissociative recombination reaction, which is essential for the excitation of the $630.0 \mathrm{~nm}$ emission under quiet geomagnetic conditions.
4.7. Figure 9, a displays changes in the ratio $I_{630.0} / I_{557.7}$, calculated from SATI-1M data; Figure 9, $b$, in $I_{N} / I_{Z}, I_{N} /\left(2 I_{Z}\right)$, and $I_{N} / I_{S}$, derived from FPI data. Solid lines in Figure 9, $b$ represent measured intensities; dotted lines are drawn taking into account the fact that at an elevation angle of $30^{\circ}$ the beam length crossing the emitting region is twice as long as at the zenith.

It is thought that the ratio $I_{630.0} / I_{557.7}$ can be used to identify the aurora type [Rassoul et al., 1993]. Mikhalev et al. [2018] have justly noted, however, that during the March 17, 2015 storm the patrol spectrograph made measurements «at small angles above the horizon». This prevents the correct use of $I_{630.0} / I_{557.7}$ for determining the type of mid-latitude aurora «because of possible latitudinal spacing of 630.0 and $557.7 \mathrm{~nm}$ emission layers». Clarifying this statement, note that it is about the difference between latitudes of emitting regions falling within the SATI-1M field of view at different heights. It is perhaps for this reason the values of $I_{630.0} / I_{557.7}>10$, characteristic of the SAR arc, were obtained in intervals 3, 4, 5, and 7, although, as shown in Figure 3, a, the arc, if emitted at $h=400 \mathrm{~km}$, could fall within the spectrograph field of view only in interval 2. Given the above, we do not use the ratio $I_{630.0} / I_{557.7}$ to determine the aurora type, but only compare its time variation with dynamics of magnetospheric-ionospheric disturbances and their manifestations in the MIT structure.

Figure 7, $a$ shows that from $14: 00$ to $15: 30$ UT the MIT depth increased from 15 to $75 \%$, and its bottom shifted to $\varphi=52.5^{\circ}$; in fact, to the latitude of GPhO. According to ionospheric sounding data, approximately at the same time, at 15:25 UT (beginning of interval 3), on ionograms there appeared F2s reflections associated with the approach to an observation point of the MIT polar wall; then, at 15:52 UT (end of interval 3), F3s reflections arising in a narrow ionization trough (see Figures 2 and 3,d).

At the moment of occurrence of F2s reflections, the MIT polar wall and bottom fell within the SATI-1M field of view at $h=200-400$ and $h=100 \mathrm{~km}$, where in interval 3 the largest synchronous increases in $I_{630.0}$ and $I_{557.7}$ were detected. Figure 9, $a$ shows that the strongest peak-shaped increase in the ratio $I_{630.0} / I_{557.7}$ to $\sim 27$ occurred in this interval. Smaller increases in $I_{630.0} / I_{557.7}$ to 17 and 12 were found in intervals 5 and 7 , in which synchronous bursts of intensities of the emissions considered were also recorded. The MIT latitudinal structure in these intervals differed markedly from that in interval 3 (Figure 9,c). In interval 5, due to the expansion of MIT to the north and south the measuring range of $I_{\mathrm{N}}$ and $T_{\mathrm{N}}$ shifted to the MIT bottom; and that of $I_{\mathrm{S}}$ and $T_{\mathrm{S}}$ neared the base of the MIT equatorial wall. In interval 7 , the zone of slightly varying TEC values, located between poorly-defined MIT walls, fell within the FPI field of view.

Comparing the plots presented in Figure 9, we can see that the peaks of $I_{630.0} / I_{557.7}$ (Figure $9, a$ ), as well as the peaks of $I_{\mathrm{N}} / I_{\mathrm{Z}}, I_{\mathrm{N}} /\left(2 I_{\mathrm{Z}}\right)$, and $I_{\mathrm{N}} / I_{\mathrm{S}}$ (Figure $\left.9, b\right)$, were observed in intervals exhibiting enhanced magnetospheric convection (top panel in Figure 9). This refers to 


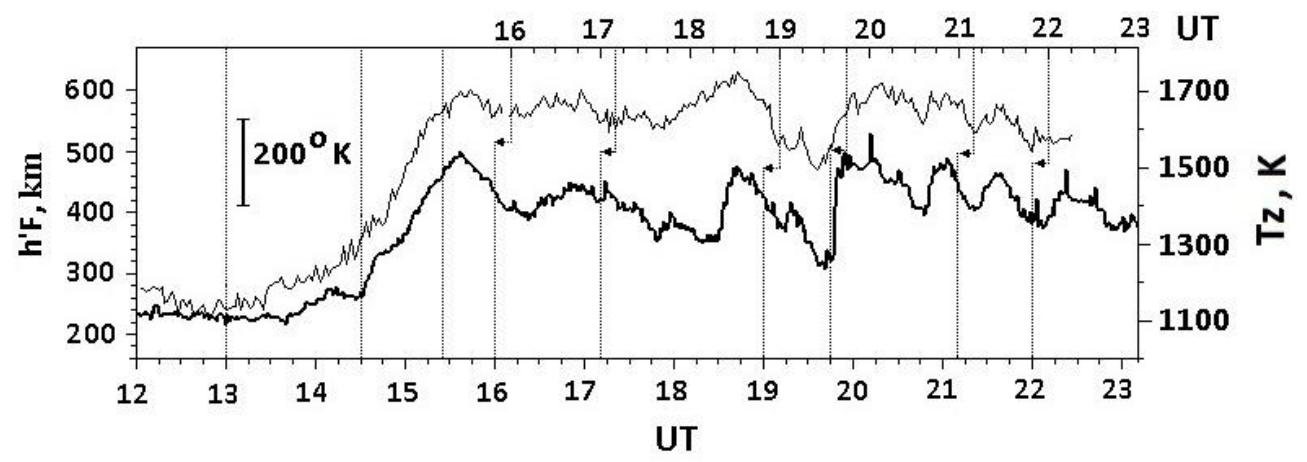

Figure 8. Variations in the minimum virtual height of the ionospheric F-region (black line) and the Doppler temperature over $\mathrm{GPhO}$ (gray line)

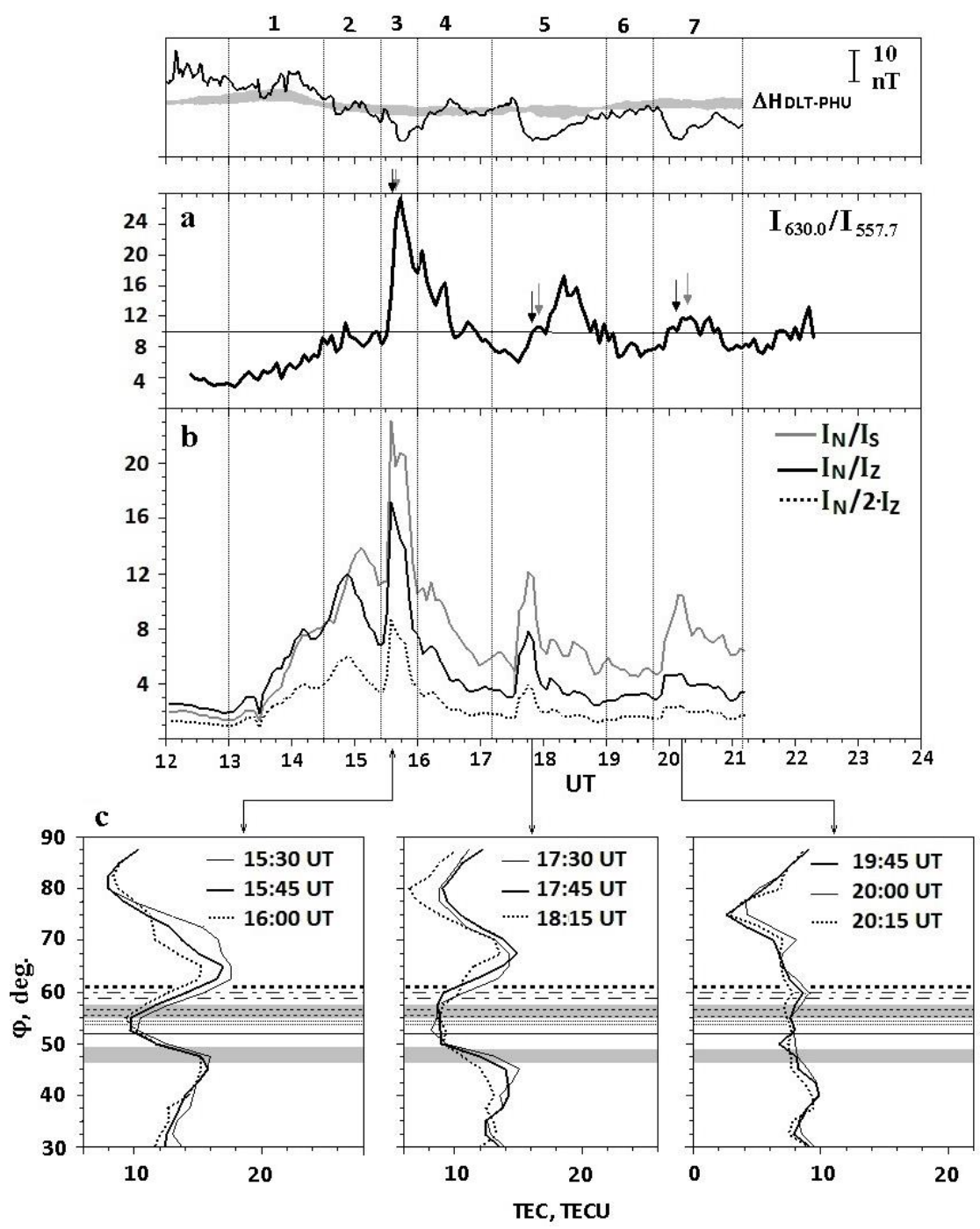

Figure 9. Variations in $I_{630.0} / I_{557.7}$ according to SATI-1M data $(a)$ and $I_{\mathrm{N}} / I_{\mathrm{Z}}, I_{\mathrm{N}} /\left(2 I_{\mathrm{Z}}\right), I_{\mathrm{N}} / I_{\mathrm{S}}(b)$, as well as latitudinal TEC profiles in intervals 3,5 , and $7(c)$. Black and gray arrows denote peaks of bursts of $I_{630.0}$ and $I_{557.7}$. For comparison, the top panel shows variations in $\Delta H_{\text {DLT-PHU }}$

the well-known tendency for the $630.0 \mathrm{~nm}$ emission intensity to increase with latitude when the magnetospheric convection is enhanced. In intervals 3, 5, and 7, the peaks of $I_{630.0}$ are respectively 3,6 , and $10 \mathrm{~min}$ ahead of those of $I_{557.7}$, which might be associated with propagation of the common zone of release of both emissions, excited at different heights, equatorward when the magnetic convection is enhanced.

The height of the $I_{630.0} / I_{557.7}$ peaks decreases from 27 in interval 3 to 17 and 12 in intervals 5 and 7 respectively. The peaks of $I_{\mathrm{N}} / I_{\mathrm{Z}}$ and $I_{\mathrm{N}} / I_{\mathrm{S}}$ decrease with time too. In interval 5, they are 2.2 and 1.9 and in interval 7, 3.8 and 2.2 times lower than in interval 3. Comparing variations in $I_{630.0} / I_{557.7}, I_{\mathrm{N}} / I_{\mathrm{Z}}$, and $I_{\mathrm{N}} / I_{\mathrm{S}}$ in intervals 3,5 , and 7 
with those depicted in Figure 9, $c$ shows that the decrease in these ratios over time might have been caused by changes in the latitudinal structure of MIT. The ratios decrease as the MIT width increases, its depth and TEC gradients on the equatorial and polar walls decrease.

Our analysis shows that we should very carefully use the ratio $I_{630.0} / I_{557.7}$ in the case of magnetic storm main phases to determine the type of mid-latitude auroras when $I_{630.0}$ and $I_{557.7}$ are measured at elevation angles much smaller than $90^{\circ}$, i.e. at different latitudes. The greatest difficulties in determining the aurora type arise if an emitting region, probed with optical instruments, is located in the MIT zone.

\section{SAR-ARC DYNAMICS}

Mikhalev et al. [2018] have demonstrated that, according to preliminary data, near the north horizon of the KEO Sentinel camera's field of view at $\sim 15: 30$ UT on March 17 an airglow band was formed which, moving equatorward, gradually took the shape of arc. This arc drifted slowly toward the equator at an average (calculated for an emission height of $\sim 400 \mathrm{~km}$ ) velocity of $\sim 20 \mathrm{~m} / \mathrm{s}$, with its structure and intensity varying. The drift velocity and dimensions of this arc matched the SAR-arc parameters reported, for example, in [Ievenko, Alekseev, 2004].

The detailed analysis of latitudinal distributions of the mean $630.0 \mathrm{~nm}$ emission intensity in the sector $\lambda=98^{\circ}$ $108^{\circ}$, carried out using KEO Sentinel data, has revealed that a structure, defined in [Mikhalev et al., 2018] as SAR arc, appeared on the background of the diffuse emission one hour earlier, at 14:30 UT (21:30 LT), at $\varphi=55.9^{\circ} \mathrm{N}$ $\left(\varphi^{\prime} \sim 51.8^{\circ}, L \sim 3.2\right)$. Figure $4, b$ indicates that at that time the depth of the horizontal magnetic component decrease in Yakutsk was equal to that observed in Tiksi. Three hours earlier, at 11:16 UT, the SAR arc emerged eastward of $\mathrm{GPhO}$ (at $\lambda \approx 130^{\circ}$ ) at approximately the same latitudes $\left(\varphi^{\prime}=52-59^{\circ}, L \sim 2.8-3.8\right)$ [Ievenko, Parnikov, 2020]. Figure 3, $a$ shows that the SAR arc could be observed with FPI in a northerly direction at 14:30-15:00 UT and the zenith at 17:30-19:00 UT.

The plots in Figure 3, $a$ and the latitudinal TEC distributions, compared with latitudinal distributions of the $630.0 \mathrm{~nm}$ emission intensity (Figure 10), denote that the $630.0 \mathrm{~nm}$ emission intensity peak corresponding to the SAR arc originally appeared near the base of the MIT polar wall (Figure 10,a). At 15:00-18:00 UT, the SAR arc was in the vicinity of the MIT bottom or near the base of its equatorial wall (Figure 10,b); and then, in the range of low TEC values slightly varying with latitude, which has been described in Section 2.2 (panel $d$ ). At 15:30 UT, the SAR-arc center was at $\Delta \varphi^{\prime} \sim 1.2^{\circ}$ northward of GPhO; at 17:30-19:00 UT, at the zenith of the observatory. According to our estimates made from KEO Sentinel data, the SAR-arc intensity in the vicinity of the zenith ranged from 100 to $300 \mathrm{R}$. We believe that the SAR-arc emission contributed to the formation of the $I_{Z}$ peak at $\sim 18: 00$ UT (interval 5) - the highest of those observed on March 17, 2015 in the zenith direction.

In most papers it is taken that the formation of a classical SAR arc is driven by the heat inflow from the inner magnetosphere in the plasmapause region (see, e.g., [Mendillo et al., 2016; Ievenko, Parnikov, 2020]). There are, however, studies showing that a SAR arc can also be formed in the polarization jet area and related narrow ionospheric trough [Khalipov et a.1, 1985; Foster et al., 1994; Sazykin et al., 2002; Chu et al., 2019]. The typical lifetime of the narrow ionization trough is $2-3 \mathrm{hr}$ [Stepanov et al., 2017]. The possibility of SAR-arc occurrence in the polarization jet area has also been discussed in [Sazykin et al., 2002]. The model calculations cited therein show that in these cases a weak arc is formed due to frictional heating of the atmosphere, which leads to an increase in the rate of dissociative recombination and to the probability of excitation of oxygen atoms in the ${ }^{1} \mathrm{D}$ state when colliding with thermal electrons. The arcs associated with the polarization jet differ from classical SAR arcs in low intensity, short lifetime, and in that they appear without significant heat inflow from the upper layers of the magnetosphere.

Several SAR arcs from different sources may exist at a time. Simultaneous detection of two or more SAR arcs was mentioned, for example, in [Ievenko et al., 2008; Hong et al., 2020]. Ievenko et al. [2008] associate the second SAR arc with the residual plasmapause. In the case we deal with, the F3s reflections indirectly indicating the presence of a narrow ionization trough near GPhO occurred at 15:52-19:00 UT (see Section 2.3.). The second SAR arc was occasionally observed from 16:00 to 19:50 UT, i.e. it appeared 68 min later than the $\mathrm{F} 3 \mathrm{~s}$ reflections and existed for $50 \mathrm{~min}$ after their disappearance. An example of the latitudinal distribution of the $630.0 \mathrm{~nm}$ emission intensity with two peaks, located southward of the MIT polar wall, is given in Figure 10, $c$. The short lifetime of the second SAR arc in our case may indicate an ionospheric source of its formation associated with the polarization jet [Sazykin et al., 2002].

There was a single SAR arc in the images captured at $\mathrm{GPhO}$ before the end of observations ( 22:30 UT, 05:30 LT). By that time, it had shifted to $\varphi=49.7^{\circ} \mathrm{N}$ ( $\left.\varphi^{\prime} \sim 45.6^{\circ}, L \sim 2\right)$. In $\sim 1.5 \mathrm{hrs}$, the presence of a SAR arc on $L \sim 2.35-2.5$ was detected in the Western Hemisphere in Millstone Hill $\left(\varphi=42.6^{\circ} \mathrm{N}, \lambda=71.4^{\circ} \mathrm{W} ; \varphi^{\prime}=52.5^{\circ}\right)$ [Hong et al., 2020]. The SAR arc was observed there for the entire period of optical measurements, made on March 18 from 00:06 to 09:47 UT (19:00-05:00 LT) during the storm recovery phase. Hong et al. [2020] have demonstrated that the SAR arc they observed was classical, formed by heat inflow from the inner magnetosphere.

Thus, according to the literature sources and our research, during the March 17-18, 2015 storm the SAR arc existed for more than $23 \mathrm{hrs}$. It appeared $5 \mathrm{hrs}$ after the onset of the storm main phase and was observed until the end of the main phase and at least for $10.5 \mathrm{hr}$ of the recovery phase. We believe that as the storm developed the role of heat inflows from the region of interaction of the ring current with the plasmasphere gradually increased and became dominant after 19:00 UT on 17 March.

\section{RESULTS}

The comprehensive analysis of geomagnetic, ionospheric, and optical phenomena has identified peculiarities of the 557.7 and $630.0 \mathrm{~nm}$ atomic oxygen emissions 

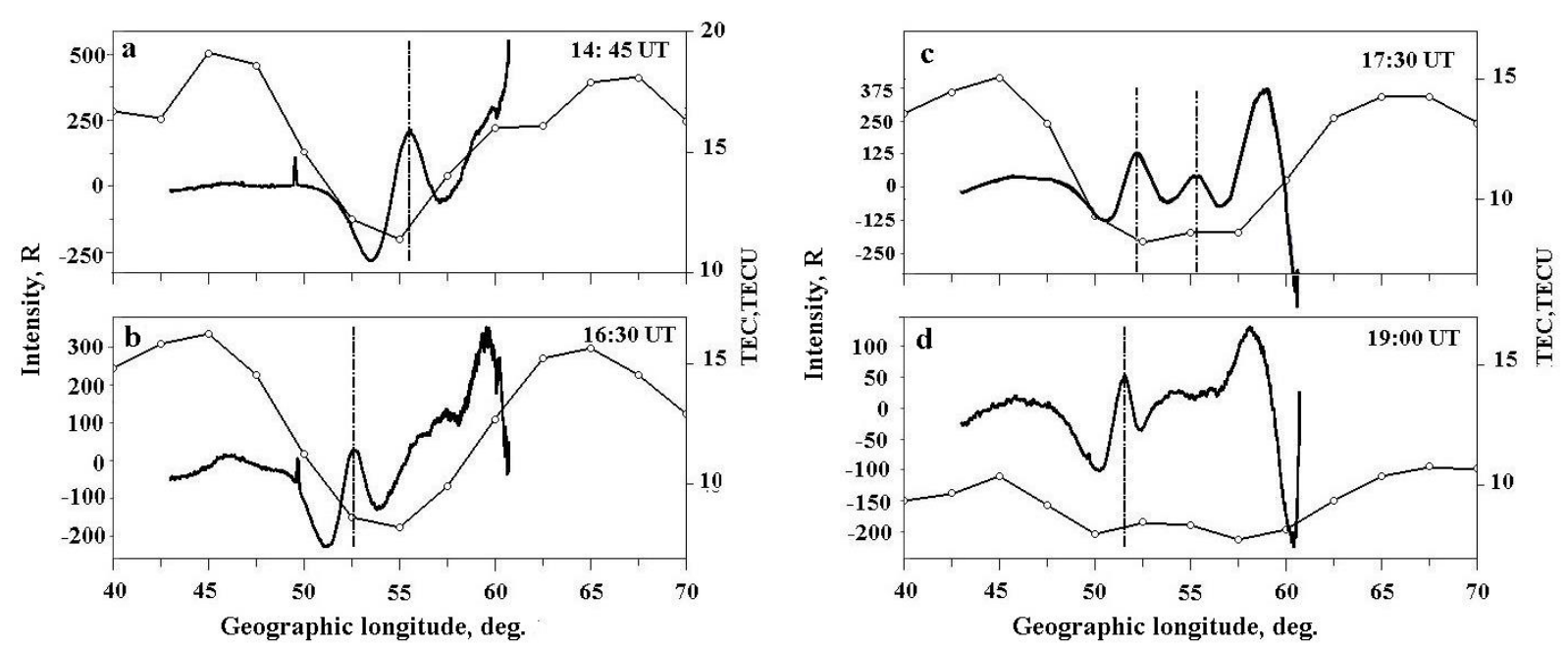

Figure 10. Latitudinal distributions of TEC (line with circles) and deviations of the $630.0 \mathrm{~nm}$ emission intensity in the SARarc center (solid line) from a component slowly varying with latitude (derived from KEO Sentinel images). The slowly varying component was separated from initial data by smoothing it by a running mean over 55 points. The time series remaining after its elimination were smoothed over 11 points. The intensity values obtained in the $98-108^{\circ} \mathrm{E}$ sector were averaged. The calculation was made for $h=400 \mathrm{~km}$. Vertical dash-dotted lines denote the latitude of intensity peaks of stable arcs

observed at the ISTP SB RAS Geophysical Observatory at 12:00-22:30 UT on March 17, 2015 during a magnetic storm.

We have shown that strengthenings of the westward electrojet occurred with an increase in the $630.0 \mathrm{~nm}$ emission intensity at all latitudes falling within fields of views of the instruments in hand. The increase in the $630.0 \mathrm{~nm}$ emission intensity was accompanied by a rise in the Doppler temperature in the cases when in the space-fixed field of view of a device were latitudes of the MIT equatorial wall or bottom.

The greatest synchronous 557.7 and $630 \mathrm{~nm}$ emission intensity increases were detected during three activations of the westward electrojet, which developed as the magnetospheric convection was enhanced.

We have found out that $I_{630.0} / I_{557.7}$ and the ratios between the $630.0 \mathrm{~nm}$ emission intensities observed in the north, zenith, and south directions depend on the position of emitting regions in these directions relative to the MIT bottom. Peaks of the ratios were maximum at 15:25-16:00 UT, when the $630.0 \mathrm{~nm}$ emission intensities in the north direction were recorded at latitudes of the MIT polar wall; the $630.0 \mathrm{~nm}$ emission intensities in the zenith and south directions and the $557.7 \mathrm{~nm}$ emissions, at latitudes of the MIT bottom and equatorial wall. The peak values decreased after latitudes of the MIT bottom fell within the devices' fields of view in a northerly direction, and went down to minimum when all the intensities were measured in the range of slightly varying small TEC values.

The SAR arc was found to appear at latitudes of the base of the MIT polar wall when the westward electrojet center began to move equatorward. Then the arc shifted to the latitudes of the MIT bottom and the base of its equatorial wall located near $\mathrm{GPhO}$ that time. In the vicinity of the zenith, the SAR-arc intensity varied from 100 to $300 \mathrm{R}$.

It is shown that $68 \mathrm{~min}$ after the appearance of $\mathrm{F} 3 \mathrm{~s}$ reflections on ionograms, the second, weaker arc, located by $2.5-3.0^{\circ}$ northward of the main one, became visible in the images captured by the all-sky camera. Judging by the presence of the F3s reflections, the primary source of the second arc might have been a polarization jet associated with a narrow ionospheric trough. The presence of two stable auroral red arcs spaced in latitude suggests the possibility of simultaneous existence of two SAR-arc sources differing in heating processes that occur in them.

Let us stress that the above results have been obtained from a study of only one strong storm and their repeatability should be checked against other magnetic storms.

The work was financially supported by the Ministry of Science and Higher Education of the Russian Federation (grant No. 075-GZ/Ts3569/278) and partially supported by RFBR grant No.19-05-00665a. The results are based on observations obtained using the equipment of Shared Equipment Center «Angara» [http://ckprf.ru/ckp/3056]. We thank the National Institutions supporting INTERMAGNET for providing high-quality data from the magnetic observatories involved in the project [www.intermagnet.org], as well as managers of ACE, GPS OMNI, and THEMIS projects for the data available on the website [http://cdaweb.gsfc.nasa.gov/istp_public].

\section{REFERENCES}

Alekseev V.N., Velichko V.A., Nadubovich Yu.A. Study of the glow heights and the position of the southern boundary of the background glow of 6300 Å. Fizika verkhney atmosfery vysokikh shirot [Physics of the Upper Atmosphere of High Latitudes]. Yakutsk, YaB of SB AS USSR Publ., 1975, vol. 3, pp. 124-133. (In Russian).

Aruliah A., Förster M., Hood R., McWhirter I., Doornbos E. Comparing high-latitude thermospheric winds from Fabry-Perot interferometer (FPI) and challenging mini-satellite payload (CHAMP) accelerometer measurements. Ann. Geophys. 2019, vol. 37, pp. 1095-1120. DOI: 10.5194/angeo-37-1095-2019. 
Balan N., Shiokawa K., Otsuka Y., Kikuchi T., Lekshmi D.V., Kawamura S., Yamamoto M., Bailey G.J. A physical mechanism of positive ionospheric storms at low latitudes and midlatitudes. $J$. Geophys. Res. 2010, vol. 115, A02304. DOI 10.1029/2009JA014515.

Bame S.J., Asbridgie J.R., Felthauseer H.E., Honesa E.W., Strong I.B. Characteristics of the plasma sheet in the Earth's magnetotail. J. Geophys. Res. 1967, vol. 72, iss. 1, pp. 113129. DOI: 10.1029/JZ072i001p00113.

BaumjohannW., Paschmann G., Cattell C.A. Average plasma properties in the central plasma sheet. J. Geophys. Res. 1989, vol 94, iss. 6, pp. 6597-6606. DOI: 10.1029/JA094iA06p06597.

Blanc M., Richmond A.D. The ionospheric disturbance dynamo. J. Geophys. Res., 1980, vol. 85, iss. A4, pp. 1669 1686. DOI: 10.1029/JA085iA04p01669.

Bryunelli B.E., Namgaladze A.A. Fizika ionosfery [Physics of ionosphere]. Moscow, Nauka Publ., 1988, 528 p. (In Russian).

Chu X., Malaspina D., Gallardo-Lacourt B., Liang J., Andersson L., Ma Q., Artemyev A., Liu J., Ergun R.E., Thaller S., Akbari H., Zhao H., Larsen B., Reeves G., Wygant J., Breneman A., Tian S., Connors M., Donovan E., Archer W., MacDonald E.A. Identifying STEVE's magnetospheric driver using conjugate observations in the magnetosphere and on the ground. Geophys. Res. Lett. 2019, vol. 46, iss. 22, pp. 12665-12674.

Deminov M.G. Ionosphere of the Earth: Features and Mechanisms. Elektromagnitnye $i$ plazmennye protsessy ot nedr Solntsa do nedr Zemli. Yubileinyi sbornik IZMIRAN-75 [Electromagnetic and Plasma Processes from the Interior of the Sun to the Interior of the Earth. Jubilee Collection IZMIRAN-75]. Moscow, 2015, pp. 295-346. (In Russian).

Deminov M.G., Shubin V.N. Empirical model of the location of the main ionospheric trough. Geomagnetism and Aeronomy. 2018, vol. 58, iss. 3, pp. 338-347. DOI: 10.1134/S0016 793218030064.

Ding G.-X., He F., Zhang X.-X., Chen B. A new auroral boundary determination algorithm based on observations from TIMED/GUVI and DMSP/SSUSI. J. Geophys. Res. 2017, vol. 122, pp. 2162-2173. DOI: 10.1002/2016JA023295.

Feldstein Y.I., Vorobjev V.G., Zverev V.L. Planetary features of aurorae: Results of the IGY (a review). Geomagnetism and Aeronomy. 2010, vol. 50, no. 4, pp. 413-435. DOI: 10.1134/ S0016793210040018.

Feldstein Y.I., Vorobjev V.G., Zverev V.L., Förster M. Investigations of the auroral luminosity distribution and the dynamics of discrete auroral forms in a historical retrospective. History GeoSpace Sci. 2014, vol. 5, pp. 81-134. DOI: 10.5194/hgss-5-812014.

Filippov V.M., Shestakova L.V., Galperin Y.I. Fast ion drift band in the subauroral F-region and its manifestation in the structure of the high-latitude ionosphere. Kosmicheskie issledovaniya [Cosmic Research]. 1984, vol. 27, no. 4, pp. 557-564. (In Russian).

Foster J.C., Buonsanto M.J., Mendillo M., Nottingham D., Rich F.J., Denig W. Coordinated stable auroral red arc observations: Relationship to plasma convection. J. Geophys. Res. 1994, vol. 99, pp. 11,429-11,439.

Frey H.U. Localized aurora beyond the auroral oval. Rev. Geophys. 2007, vol. 45, RG1003. DOI: 10.1029/2005RG000174.

Gonzalez W.D., Tsurutani B.T., Lepping R.P., Schwenn R. Interplanetary phenomena associated with very intense geomagnetic storms. J. Atmos. Solar-Terr. Phys. 2002, vol. 64, pp. 173-181.

Gussenhoven M.S., Hardy D.A., Heinemann N. Systematics of the equatorward diffuse auroral boundary. J. Geophys. Res. 1983, vol. 88, iss. A7, pp. 5692-5708.

Hairston M., Coley W.R., Stoneback R. Responses in the polar and equatorial ionosphere to the March 2015 St. Patrick Day storm. J. Geophys. Res. 2016, vol. 121, pp. 11,21311,234. DOI: 10.1002/2016JA023165.
He M., Liu L., Wan W., Zhao B. A study on the nighttime midlatitude ionospheric trough. J. Geophys. Res., 2011, vol. 116, iss. A5, A05315. DOI: 10.1029/2010JA016252.

Hong J., Kim Y.H., Kam H.., Chung J.-K., Park J., Kim J.-H., Mendillo M. Simultaneous observations of SAR arc and its ionospheric response at subauroral conjugate points $(L \approx 2.5)$ during the St. Patrick's Day Storm in 2015. J. Geophys. Res. 2020, vol. 124, iss. 4. DOI: 10.1029/2019JA027321.

Ievenko I.B., Alekseev V.N. Effect of the substorm and storm on the sar arc dynamics: A statistical analysis. Geomagnetism and Aeronomy. 2004, vol. 44, no. 5, pp. 592-603.

Ievenko I.B., Parnikov S.G., Alexeyev V.N. Relationship of the diffuse aurora and SAR arc dynamics to substorms and storms. Adv. Space Res. 2008, vol. 41, no. 8, pp. 1252-1260. DOI: $10.1016 / j . a s r .2007 .07 .030$.

Ievenko I.B., Parnikov S.G. Ground-based and satellite observations of the SAR-arc in the MLT evening sector at the beginning of the magnetic storm on March 17, 2015. Geomagnetism and Aeronomy. 2020, vol. 60, no 6, pp. 737-746. DOI: $10.1134 /$ S0016793220050096.

Jacobsen K.S., Andalsvik Y.L. Overview of the 2015 St. Patrick's Day storm and its consequences for RTK and PPP positioning in Norway. J. Space Weather Space Climate. 2016, vol. 6, A9. DOI: 10.1051/swsc/2016004.

Keika K., Nakamura R., Baumjohann W., Angelopoulos V., Chi P.J., Glassmeier K.H., Fillingim M., Magnes W., Auster H.U., Fornacon K.H., Reeves G. D., Yumoto K., Lucek E.A., Carr C.M., Dandouras I. Substorm expansion triggered by a sudden impulse front propagating from the dayside magnetopause. J. Geophys. Res. 2009, vol. 114, A00C24. DOI: 10.1029/ 2008JA013445.

Khalipov V.L., Sivtseva L.D., Filippov V.M., Stepanov A.E., Nikolaenko L.M., Bosqued J.M., Beghin C. Step-like profiles of electron density in the subauroral lower F-region in the morning sector and possible mechanisms of their formation during substorms: the comparison of data of ground-based ionosondes with the AUREOL-3 satellite measurements. Results of the ARCAD 3 project and of the recent programmes in magnetospheric and ionospheric physics, Toulouse, 1984. Toulouse, Cepadueseditions, 1985, pp. 895-916.

Khalipov V.L., Stepanov A.E., Ievenko I.B., Kotova G.A., Panchenko V.A. Formation of red arc in the polarization jet band. J. Atmos. Solar-Terr. Phys. 2018, vol. 179, pp. 494-503. DOI: $10.1016 / j$.jastp.2018.08.005.

Khomich V.Yu., Semenov A.I., Shefov N.N. Airglow as an Indicator of Upper Atmospheric Structure and Dynamics. Springer-Verlag Berlin Heidelberg, 2008, 756 p.

Kosar B.C., MacDonald E.A., Case N.A., Zhang Y., Mitchell E.J., Viereck R. A case study comparing citizen science aurora data with global auroral boundaries derived from satellite imagery and empirical models. J. Atmos. Solar-Terr. Phys. 2018, vol. 177, pp. 274-282. DOI: 10.1016/j.jastp.2018.05.006.

Le G., Lühr H., Anderson B.J., Strangeway R.J., Russell C.T., Singer H., Slavin J.A., Zhang Y., Huang T., Bromund K., Chi P.J., Lu G., Fischer D., Kepko E.L., Leinweber H.K., Magnes W., Nakamura R., Plaschke F., Park J., Rauberg J., Stolle C., Torbert R.B. Magnetopause erosion during the March 17, 2015 magnetic storm: Combined field-aligned currents, auroral oval, and magnetopause observations. Geophys. Res. Lett. 2016, vol. 43, iss. 4, pp. 2396-2404. DOI: 10.1002/ 2016GL068257.

McPherron R.L. The use of ground magnetograms to time the onset of magnetospheric substorms. Journal of Geomagnetism and Geoelectricity. 1978, vol. 30, pp.149-163.

Megan Gillies D., Knudsen D., Donovan E., Jackel B., Gillies R., Spanswick E. Identifying the $630 \mathrm{~nm}$ auroral arc emission height: A comparison of the triangulation, FAC profile, and electron density methods. J. Geophys. Res. 2017, vol. 122, pp. 8181-8197. DOI: 10.1002/2016JA023758. 
Mendillo M. Storms in the ionosphere: Patterns and processes for total electron content. Rev. Geophys. 2006, vol. 44, iss. 4, RG4001. DOI: 10.1029/2005RG000193.

Mendillo M., Baumgardner J., Wroten J., Martinis C., Smith S., Merenda K.D., Fritz T., Hairston M., Heelis R., Barbieri C. Imaging magnetospheric boundaries at ionospheric heights. J. Geophys. Res. 2013, vol. 118, iss. 11, pp. 7294 7305. DOI: 10.1002/2013JA019267.

Mendillo M., Finan R., Baumgardner J., Wroten J., Martinis C., Casillas M. A stable auroral red (SAR) arc with multiple emission features. J. Geophys. Res. 2016, vol. 121, pp. 10,564-10,577. DOI: 10.1002/2016JA023258.

Meurant M., Gerard J.-C., Blockx C., Hubert B., Coumans V. Propagation of electron and proton shock-induced aurora and the role of the interplanetary magnetic field and solar wind $J$. Geophys. Res. 2004, vol. 109, A10210. DOI: 10.1029/2004 JA010453.

Mikhalev A.V. Mid-latitude aurora in solar cycles 23-24 from observations in the south of Eastern Siberia. Solar-Terr. Phys. 2019, vol. 5, iss. 4, pp. 66-73. DOI: 10.12737/stp54201909.

Mikhalev A.V., Beletsky A.B., Vasilyev R.V., Zherebtsov G.A., Podlesny S.V., Tashchilin M.A., Artamonov M.F. Spectral and photometric characteristics of mid-latitude auroras during the magnetic storm of March 17, 2015. Solar-Terr. Phys. 2018, vol. 4, iss. 4, pp. 42-47. DOI: $10.12737 /$ stp-44201806.

Mishin V.V., Lunyushkin S.B., Mikhalev A.V., Klibanova Yu.Yu., Tsegmed B., Karavaev Yu.A., Tashchilin A.V., Leonovich L.A., Penskikh Yu.V. Extreme geomagnetic and optical disturbances over Irkutsk during the 2003 November 20 superstorm. J. Atmos. Solar-Terr. Phys. 2018, vol. 181, pt. A, pp. 68-78. DOI: 10.1016/j.jastp.2018.10.013.

Moldwin M.B., Downward L., Rassoul H.K., Amin R.R., Anderson R.R. A new model of the location of the plasmapause: CRRES results. J. Geophys. Res. 2002, vol. 107, iss. A11, pp. SMP 2-1-SMP 2-9. DOI: 10.1029/2001JA009211.

Nagai T., Baker D.N., Higbie P.R. Development of substorm activity in multiple-onset substorms at synchronous orbit. J. Geophys. Res. 1983, vol. 88, iss. A9, pp. 6994-7004.

Newell P.T., Sotirelis T., Wing S. Diffuse, monoenergetic, and broadband aurora: The global precipitation budget. $J$. Geophys. Res. 2009, vol. 114, A09207. DOI: 10.1029/2009 JA014326.

Ni B., Thorne R.M. Zhang X., Bortnik J., Pu Z., Xie L., $\mathrm{Hu}$ Z., Han D., Shi R., Zhou C., Gu X. Origins of the Earth's Diffuse Auroral Precipitation. Space Sci Rev. 2016, vol. 200, pp. 205-259. DOI: 10.1007/s11214-016-0234-7.

Podlesnyi A.V., Brynko I.G., Kurkin V.I., Berezovsky V.A., Kiselyov A.M., Petuchov E.V.Multifunctional chirp ionosonde for monitoring the ionosphere. Geliogeofizicheskie issledovaniya [Heliogeophysical Research]. 2013, iss. 4, pp. 24-31. Available at: http://vestnik.geospace.ru/index.php?id=166 (Accessed 10 November 2020). (In Russian).

Polekh N., Zolotukhina N., Kurkin V., Zherebtsov G., Shi J., Wang G., Wang Z. Dynamics of ionospheric disturbances during the 17-19 March 2015 geomagnetic storm over East Asia. Adv. Space Res. 2017, vol. 60, iss. 11, pp. 2464-2476. DOI: 10.1016/j.asr.2017.09.030.

Polekh N.M., Zolotukhina N.A., Romanova E.B., Ponomarchuk S.N., Kurkin V.I., Podlesnyi A.V. Ionospheric effects of magnetospheric and thermospheric disturbances on March 17-19, 2015. Geomagnetism and Aeronomy. 2016, vol. 56, no. 5, pp. 557-571. DOI: 10.1134/S0016793216040174.

Pryse S.E., Kersley L., Malan D., Bishop G.J. Parameterization of the main ionospheric trough in the European sector. $R a$ dio Sci. 2006, vol. 41, RS5S14. DOI: 10.1029/2005RS003364.
Rassoul H.K., Rohrbaugh R.P., Tinsley B.A., Slater D.W. Spectrometric and photometric observations of low-latitude aurorae. J. Geophys. Res. 1993, vol. 98, iss. A5, pp. 76957709. DOI: $10.1029 / 92 J A 02269$.

Sazykin S., Fejer B.G., Galperin Yu.I., Zinin L.V., Grigoriev S.A., Mendillo M. Polarization jet events and excitation of weak SAR arcs. Geophys. Res. Lett. 2002, vol. 29, iss. 12, pp. 26-1-26-4. DOI: 10.1029/2001GL014388.

Shinbori A., OtsukaY., Tsugawa T., Nishioka M., Kumamoto A., Tsuchiya F., Matsuda S., Kasahara Y., Matsuoka A., Ruohoniemi J.M., Shepherd S.G., Nishitani N. Temporal and spatial variations of storm time midlatitude ionospheric trough based on global GNSS-TEC and Arase satellite observations. Geophys. Res. Lett. 2018, vol. 45, pp. 7362-7370. DOI: 10.1029/2018GL078723.

Shiokawa K., Ogawa T., Kamide Y. Low-latitude auroras observed in Japan: 1999-2004. J. Geophys. Res. 2005, vol. 110, A05202. DOI: 10.1029/2004JA010706.

Shindin A.V., Klimenko V.V., Kologin D.A., Beletsky A.B., Grach S.M., Nasyrov I.A., Sergeev E.N. Spatial characteristics of the 630-nm artificial airglow generation region during the Sura facility pumping. Radiophysics and Quantum Electronics. 2018 , vol. 60 , no. 11 , pp. 849-865. DOI: $10.1007 /$ s11141-0189852-0.

Suzuki H., Chino H., Sano Y., Kadokura A., Ejiri M.K., Taguchi M. Imaging-based observations of low-latitude auroras during 2001-2004 at Nayoro, Japan. Earth, Planets and Space. 2015, vol. 67, 107. DOI: 10.1186/s40623-015-0278-z.

Starkov G.V. Planetarnaya dinamika avroral'nogo svecheniya. Fizika okolozemnogo kosmicheskogo prostranstva. T. 1 [Planetary Dynamics of the Aurora. Physics of Near-Earth Space. Vol. 1]. Apatity, Publishing House of the Kola Scientific Center of RAN, 2000, 706 p. (In Russian).

Stepanov A.E., Khalipov V.L., Golikov I.A., Bondar E.D. Polyarizatsionnyi dzhet: uzkie i bystrye dreify subavroral'noi ionosfernoi plazmy [Polarization Jet: Narrow and Fast Drifts of Subauroral Ionospheric Plasma]. Yakutsk, Publishing House of the NEFU, 2017, 176 p. (In Russian).

Tashchilin A.V., Leonovich L.A. Modeling nightglow in atomic oxygen red and green lines under moderate disturbed geomagnetic conditions at midlatitudes. Solar-Terr. Phys. 2016, vol. 2, iss. 4, pp. 94-106. DOI: 10.12737/24276.

Tsurutani B.T., Lakhina G.S., Verkhoglyadova O.P., Gonzalez W.D., Echer E., Guarnieri F.L. A review of interplanetary discontinuities and their geomagnetic effects. J. Atmos. Solar-Terr. Phys. 2011, vol. 73, pp. 5-19. DOI: 10.1016/j.jastp. 2010.04.001.

Vasilyev R.V., Artamonov M.F., Beletsky A.B., Zherebtsov G.A., Medvedeva I.V., Mikhalev A.V., Syrenova T.E. Registering upper atmosphere parameters in East Siberia with Fabry-Perot Interferometer KEO Scientific "Arinae". Solar-Terr. Phys. 2017, vol. 3, iss. 3, pp. 61-75. DOI: 10.12737/stp-33201707.

Zherebtsov G.A., Pirog O.M., Razuvayev O.I. The highlatitude ionosphere structure and dynamics. Issledovaniya po geomagnetizmu, aeronomii i fizike Solntsa [Research on Geomanetism, Aeronomy and Solar Physics]. 1986, iss. 76, pp. 165-177. (In Russian).

Zolotukhina N.A., Kurkin V.I., Polekh N.M., Romanova E.B. Backscattering dynamics during intense geomagnetic storm as deduced from Yekaterinburg radar data: 17-22 March 2015. Solar-Terr. Phys. 2016, vol. 2, iss. 4, pp. 31-54. DOI: 10.12737/ 24272.

Zolotukhina N., Polekh N., Kurkin V., Rogov D., Romanova E., Chelpanov M. Ionospheric effects of St. Patrick's storm over Asian Russia: 17-19 March 2015. J. Geophys. Res. 2017, vol. 122, pp. 2484-2504. DOI: 10.1002/2016JA023180. 
Zverev V.L., Feldstein Y.I., Vorobjev V.G. Auroral glow equatorward from the auroral oval. Geomagnetism and Aeronomy. 2012, vol. 52, no. 1, pp. 60-67. DOI: 10.1134/ S0016793212010173.

URL: https://www.swpc.noaa.gov/noaa-scales-explanation (accessed April 2, 2021).

URL: https://www.intermagnet.org/data-donnee/downloadeng.php (accessed October 16, 2015).

URL: ftp.swpc.noaa.gov/pub/warehouse (accessed October 15, 2015).

URL: https://www.ngdc.noaa.gov/stp/ovation_prime/data (дата обращения March 20, 2020).

URL: http://ckprf.ru/ckp/3056 (accessed April 15, 2015).

URL: www.intermagnet.org (accessed March 21, 2015).

URL: http://cdaweb.gsfc.nasa.gov/istp_public (accessed July 15, 2015)

How to cite this article

Zolotukhina N.A., Polekh N.M., Mikhalev A.V., Beletsky A.B., Podlesny S.V. Peculiarities of 630.0 and $557.7 \mathrm{~nm}$ emissions in the main ionospheric trough: March 17, 2015. Solar-Terrestrial Physics. 2021. Vol. 7. Iss. 3. P. 53-67. DOI: 10.12737/stp-73202105. 